\title{
Foreign Aid and Weakest-Link International Public Goods: An Experimental Study
}

\author{
Vivian Lei ${ }^{a,{ }^{*}}$, Steven Tucker $^{\mathrm{b}}$, and Filip Vesely ${ }^{\mathrm{c}}$ \\ ${ }^{a}$ Department of Economics, University of Wisconsin-Milwaukee, USA \\ ${ }^{b}$ Department of Economics, University of Canterbury, New Zealand \\ ${ }^{c}$ Department of Economics, University of Wisconsin-Milwaukee, USA
}

\begin{abstract}
In this paper, we investigate efficiency differences between income and in-kind transfers as distribution mechanisms of foreign aid to weakest-link international public goods in a laboratory environment. We find that if there is relatively small difference in country size, then income transfers seem to provide a higher provision of the international public good, and thus higher overall welfare level than that of in-kind transfers. However, if there is a large disparity in country size, then in-kind transfers appear to provide a higher level of IPG provision and higher accompanying global welfare.
\end{abstract}

JEL classification: D70; H41; C90

Keywords: Foreign aid; Public goods; Weakest-Link; Neutrality; Experiments

\footnotetext{
* Corresponding author. Address: 3210 N. Maryland Ave., Bolton Hall 818, Milwaukee, WI 53201, USA; phone: (414) 229-6494; fax: (414) 229-3860; e-mail: vlei@uwm.edu.

Acknowledgements: We are grateful to the University of Canterbury Economics Department and University of Canterbury Research Center for financial support. Travel support from Center for Research on International Economics and Center for International Education at University of Wisconsin-Milwaukee is greatly appreciated. We thank Tim Cason, Enrique Fatas, Werner Guth, Andrew Muller, Charles Noussair, Tatsuyoshi Saijo, two anonymous referees, seminar participants at University of Wisconsin-Milwaukee, participants at the 2004 North American Meeting of the Economic Science Association, the 2004 International Economic Science Association Meeting, and the International Conference on Experimental Methods in Economics, Finance and Management for helpful comments.
} 


\section{Introduction}

There has been a renewed interest in foreign aid, particularly over the past few years, as a means to help poor countries finance international public goods (IPG), i.e. goods that provide benefits which have transnational reach. According to the World Bank (2001), the percentage of total official development assistance that was spent on IPGs rose from 1.5 percent in the 1970s to almost 8 percent in 1999. In the second half of the 1990s, developed countries transferred approximately $\$ 2$ billion a year to finance the core IPG's activities such as contagious disease control, biodiversity protection, and peacekeeping in the developing world.

Public good aid generally takes the form of either income transfers or in-kind transfers. A typical example of an in-kind transfer is the 2003 dispatch of medical teams by the Centers for Disease Control and Prevention to help control the outbreak of SARS in Asia. The effectiveness of foreign aid to an IPG is largely dependent upon the aggregation technology of the public good. For instance, when the aggregation technology is best shot-the provision level of an IPG is determined by the largest individual effort - it may be in developed countries' best interest to assume the leading role in providing the optimal level of such IPGs and limit resources transferred to developing countries. Examples of best-shot IPGs are the efforts devoted towards a research breakthrough for a cure of cancer, an infectious disease, etc.... On the contrary, when the provision of an IPG is determined by the smallest individual contribution, the so-called weakest-link technology, there are greater incentives for the rich to assist the poor so as to boost the provision of an IPG. Fighting against international terrorism and eradicating contagious diseases such as AIDS are examples of weakest-link IPGs. Without foreign aid, the success of preventing, say, AIDS from further spreading around the world would be constrained not only by the limited resources available in countries such as Nigeria, Kenya, and Thailand to finance 
programs that fight the deadly disease, but also by their capacities to implement these programs. Clearly, the effectiveness of fighting AIDS under such a circumstance would not be satisfactory. Thus, to win the worldwide combat against AIDS and ensure the health of their own citizens, rich countries such as the U.S., U.K., and Japan have a good incentive to assist the poor. ${ }^{1}$ As noted by Vicary (1990), foreign transfers used to finance weakest-link public goods under certain circumstances "involve no altruism on the part of donors, and are made simply to maximize donors' utilities."

Acknowledging the importance of foreign aid in augmenting the provision of weakestlink IPGs, we focus our investigation on the effectiveness of foreign aid when the aggregation technology of a public good takes the form of weakest-link. More specifically, we are interested in the effectiveness of the two transfer schemes - income vs. in-kind transfers-in providing weakest-link IPGs and improving global welfare. There have been a few theoretical studies on this topic. Jayaraman and Kanbur (1999) show that there exists a condition under which both countries are better off by a resource transfer from the rich to the poor, and that the neutrality theorem (Warr, 1983) holds in a post-transfer equilibrium, i.e. the donor and the recipient are indifferent between aid in the form of income or in-kind transfers. ${ }^{2}$ The neutrality theorem is satisfied regardless of whether the game is organized in a simultaneous-contribution framework or a leader-follower setup. Vicary and Sandler (2002) show that in a two-stage two-country game where agents decide cash transfers in the first stage and contributions to the public goods to either country in the second stage, income transfers may be Pareto superior to in-kind transfers when two countries are equally efficient in producing the public goods.

\footnotetext{
${ }^{1}$ According to OECD (2004), the U.S. was the largest bilateral donor in the combat of fighting HIV/AIDS with contributions around $\$ 793$ million per year (2000-2002). It is followed by the U.K. (\$337 million) and Japan (\$161 million).

${ }^{2}$ In their model, two countries share the same preferences but differ in their endowments.
} 
The primary objective of this study is to investigate whether the neutrality theorem is supported in a laboratory environment. More specifically, we compare two transfer mechanisms and two levels of endowment asymmetry in order to address the following research questions: (1) Are in-kind and income transfers equally effective in promoting adequate provision of a weakest-link IPG, and thus increasing the welfare of the rich as well as of the poor? (2) Does the degree of endowment asymmetry between donors and recipients play any role in determining the efficacy of these two transfer mechanisms? We believe these questions have tremendous implications on designing appropriate policy tools to improve both donors' and recipients' wellbeings.

To answer these questions, we adopt a $2 \times 2$ design where the treatment variables are the foreign aid scheme and the endowment difference. The two aid schemes are income and in-kind transfers. There are two endowment conditions that capture the disparity in endowments between two paired individuals: weak asymmetry (WA) and strong asymmetry (SA). The game in our experiment is structured as a two-stage two-country game. In the first stage, agents simultaneously decide the fraction of their endowment which they would like to transfer to their counterpart. The aid is either an income or in-kind transfer. In stage two, agents simultaneously decide the allocation of their post-transfer wealth between their personal consumption and contribution to the public good in their own country. The level of the IPG is determined by the smaller of the total contributions between the two public goods. The parameters of endowments and payoff functions are carefully chosen so that unique Pareto (sub-game) perfect equilibrium payoffs exist in all four treatments (in-kind/WA, income/WA, in-kind/SA, and income/SA), and that the neutrality theorem is satisfied in this unique equilibrium. Furthermore, the equilibrium 
payoffs are identical under both SA and WA endowment conditions. Based on our theoretical predications, we propose the following hypotheses for evaluation:

Hypothesis 1: For either level of endowment asymmetry, both poor and rich countries are indifferent between the outcomes with in-kind transfers and the outcomes with income transfers.

Hypothesis 2: For either type of transfer scheme, both poor and rich countries are indifferent between the outcomes under weakly asymmetric endowment condition and the outcomes under strongly asymmetric endowment condition.

Hypothesis 3: The outcomes of all treatments are identical to those predicted by the Pareto perfect equilibrium solution.

Following the above investigation, a question that is of interest is, if one aid mechanism proves to be more effective than the other when offered exclusively, will this same mechanism be the chosen one when both schemes are available simultaneously. We have two additional treatments (both/WA and both/SA) to examine this particular issue.

As reported in detail in Sections 4 and 5, the weakest-link IPG is generally under provided in our experiment. The under provision problem is not unusual in the experimental literature on weakest-link games. ${ }^{3}$ What is of particular interest in our results is that none of the hypotheses is supported by our data. The neutrality theorem is refuted. Income and in-kind transfers appear to possess distinct efficacies under different endowment environments. Under

\footnotetext{
${ }^{3}$ See Camerer (2003) for a survey on weakest-link games.
} 
SA, in-kind transfers tend to generate a higher provision of the IPG and thus induce larger global welfare than income transfers. In contrast, income transfers are more effective than in-kind transfers under WA. Finally, when both types of foreign aid are available simultaneously, we find that, although it is not always in rich countries' best interests to do so, in-kind transfers are their predominant choice regardless of the endowment environment.

Due to the limited field data which can be used directly to test the neutrality theorem, we believe that experimental methods are a more useful tool to tackle the issues we intend to study here. Nevertheless, just like many other experimental laboratory studies, we are vulnerable to criticisms of oversimplification. Therefore, acknowledging the fact that our design does not capture the complexities of international politics, readers should note that the main objective of this study is to test a mathematically defined theory, regardless of the context.

The rest of our paper is organized as follows. The theoretical model is presented in Section 2. Section 3 describes the experimental design and procedures. The results are reported in Sections 4 and 5. Finally, Section 6 concludes the paper.

\section{The Model}

For simplicity, assume that there exist only two countries that share the same utility function but differ in their endowments. The poor country $(P)$ has endowed wealth $w_{P}=\beta w$, and the rich country $(R)$ has endowed wealth $w_{R}=(1-\beta) w$, where $w>0$ and $\beta \in[0,1 / 2)$. The utility function takes the following Cobb-Douglas form:

$$
u_{i}=A c_{i}^{1-\alpha} G^{\alpha},
$$

where $c_{i}$ is personal consumption, $G$ is an international public good (IPG), $A>0$, and $\alpha \in(0,1)$. 
In a conventional weakest-link public good game, the provision of the public good is determined by the lowest individual contribution (Hirshleifer, 1983). Therefore, the objective of country $i$ is to maximize its utility function, subject to the budget constraint $w_{i}=c_{i}+g_{i}$ as well as the weakest-link aggregation technology $G=\min \left\{g_{R}, g_{P}\right\}$, where $g_{i}$ denotes country $i$ 's contribution to the public good. It follows from the Cobb-Douglas utility function that country $i$ 's best response to country $j$ 's contribution, $g_{j}$, is to contribute:

$$
g_{i}\left(g_{j}\right)=\min \left\{g_{j}, \alpha w_{i}\right\}
$$

Although each country contributes at most $\alpha w_{i}$, the maximal contribution that satisfies equation (2) for both countries is, in fact, constrained by $\alpha w_{P}=\alpha \beta w$. In addition, since equation (2) also holds for any contribution smaller than $\alpha \beta w$, this game has multiple equilibria. These multiple equilbria are given by $c_{i}^{*}=w_{i}-G^{*}$, where $g_{P}^{*}=g_{R}^{*}=G^{*}$ and $G^{*} \in[0, \alpha \beta w]$. That is, when the aggregation technology takes the form of weakest-link, equilibrium is characterized by a matching behavior between the two countries in the sense that the provision of the public good in one country is the same as that in the other. Note that the equilibrium in which $G^{*}=\alpha \beta w$, $c_{P}^{*}=(1-\alpha) \beta w$, and $c_{R}^{*}=(1-\beta-\alpha \beta) w$ Pareto dominates all other equilibria. In other words, the level of the IPG at this Pareto dominant equilibrium is determined solely by the endowment of the poor country. This would change once international transfers are allowed. 


\subsection{Two-Stage Weakest-Link IPG with Income Transfers}

Consider the following two-stage game that has the same structure as in Vicary and Sandler (2002). During the first stage, countries are allowed to transfer their endowments to their counterparts. During the second stage, countries play the previously described weakest-link IPG game. Assuming that countries would never play a Pareto-dominated equilibrium in any subgame, we restrict our attention to Pareto (sub-game) perfect equilibria that are defined as the following:

Definition. A pair of strategies is a Pareto (sub-game) perfect equilibrium if the strategies, when confined to any sub-game of the original game, have the countries playing a Pareto dominant equilibrium within that sub-game.

Let $s_{i} \in\left[0, w_{i}\right]$ denote an income transfer from country $i$ to country $j$. Country $i$ 's budget constraint becomes $w_{i}+s_{j}-s_{i}=c_{i}+g_{i}$, and its best response function in the second stage is:

$$
g_{i}\left(g_{j}\right)=\min \left\{g_{j}, \alpha\left(w_{i}+s_{j}-s_{i}\right)\right\}
$$

The Pareto-dominant equilibrium of the second stage is once again given by the wealth of the country that is poorer at the beginning of this post-transfer stage. Also note that the poorer country's utility increases with its wealth. As a result, the rich country in the Pareto perfect equilibrium would never want to transfer a fraction of its wealth large enough so that it becomes the poorer of the two at the beginning of the second stage. By the same token, the poor country would never want to transfer anything to its rich counterpart. The level of the IPG in this case is then given by $G=\alpha\left(w_{P}+s_{R}\right)$. So, by backward induction, the problem that the rich country has to solve in the first stage is to choose an amount of foreign aid $s_{R}$ which maximizes its own 
utility $u_{R}$ given the budget constraint $w_{R}-s_{R}=c_{R}+G$. The solution yields a unique Pareto perfect equilibrium, in which the equilibrium path strategies are

$$
\begin{aligned}
& \left\{s_{P}^{*}, s_{R}^{*}, c_{P}^{*}, c_{R}^{*}\right\}=\{0,0, \quad(1-\alpha) \beta w, \quad(1-\beta-\alpha \beta) w\}, \quad \text { if } \beta>\beta_{0}, \\
& \left\{0,\left(\beta_{0}-\beta\right) w,(1-\alpha) \beta_{0} w,\left(1-\beta_{0}-\alpha \beta_{0}\right) w\right\}, \quad \text { if } \beta \leq \beta_{0} \text {, }
\end{aligned}
$$

where $\beta_{0}=\alpha /(1+\alpha)$. Equation (4a) implies that the rich country would not benefit from providing any income transfers if the difference between two countries' endowments is relatively small. On the contrary, if two countries are more asymmetric from each other as indicated by equation (4b), both countries would benefit from an income transfer from the rich to the poor. The post-transfer wealth of the poor and the rich are $\beta_{0} w$ and $\left(1-\beta_{0}\right) w$, respectively. Therefore, as long as the condition of (4b) holds - meaning the poor country's endowment is less than $\beta_{0} w$ - the level of the IPG and personal consumptions are always given by:

$$
G^{*}=\alpha \beta_{0} w, c_{P}^{*}=(1-\alpha) \beta_{0} w, \text { and } c_{R}^{*}=\left(1-\beta_{0}-\alpha \beta_{0}\right) w
$$

regardless of how much further the asymmetry is between the two countries.

\subsection{Two-Stage Weakest-Link IPG with In-Kind Transfers}

Consider a two-stage game similar to that in section 2.1 , but with transfers directly contributed to the public good in the recipient country. Let $h_{i}$ denote country $i$ 's in-kind transfer to country $j$ 's public good. Country $i$ 's budget constraint becomes $w_{i}=c_{i}+g_{i}+h_{i}$, and the IPG provision is determined by $G=\min \left\{g_{R}+h_{P}, g_{P}+h_{R}\right\}$. Note that for country $i$, the optimal contribution to its own public good is $\min \left\{h_{i}+g_{j}, \alpha\left(w_{i}+h_{j}-h_{i}\right)\right\}-h_{j}$ if this difference is 
positive, or zero otherwise. In other words, country $i$ 's best response function in the second stage is given by:

$$
g_{i}\left(g_{j}\right)=\max \left\{0, \min \left\{h_{i}+g_{j}-h_{j}, \alpha\left(w_{i}+h_{j}-h_{i}\right)-h_{j}\right\}\right\} .
$$

Since the poor country would not benefit from transferring any of its endowment to the rich country, $h_{P}=0$. It follows from equation (6) that, in a Pareto perfect equilibrium, $G=\max \left\{h_{R}, \alpha\left(w_{P}+h_{R}\right)\right\}$.

We must now calculate the optimal in-kind transfer by the rich country. In the first stage, the rich country chooses $h_{R}$ which maximizes $u_{R}$ given the budget constraint $w_{R}-h_{R}=c_{R}+G$. The solution renders a unique Pareto perfect equilibrium with the equilibrium-path strategies:

$$
\begin{array}{rlrlrl}
\left\{h_{P}^{*}, h_{R}^{*}, c_{P}^{*}, c_{R}^{*}\right\}= & \{0,0, & (1-\alpha) \beta w, & (1-\beta-\alpha \beta) w\}, & & \text { if } \beta>\beta_{1}, \\
& \left\{0,\left(\beta_{0}-\beta\right) w,\right. & (1-\alpha) \beta_{0} w, & \left.\left(1-\beta_{0}-\alpha \beta_{0}\right) w\right\}, & \text { if } \beta \in\left(\beta_{2}, \beta_{1}\right], \\
& \{0, \alpha(1-\beta) w / 2, & \beta w, & (1-\alpha)(1-\beta) w\}, & \text { if } \beta \leq \beta_{2}
\end{array}
$$

It can be shown that there exists $\theta \approx 0.25857$ such that $\beta_{2}=1-[2 \alpha /(1+\alpha)]^{\alpha}<\beta_{1}=\beta_{0}$ if $\alpha>\theta$. Equation (7a), which is identical to equation (4a), implies that when the poor country's endowment is very close to the rich country's, in-kind transfers are not beneficial for the rich, and thus the level of the IPG depends only on the poor country's endowment. On the other hand, when the poor country's endowment is much smaller than that of the rich, equation (7c) implies that only the rich country would contribute to the public goods, domestic and abroad. Therefore, it is the rich country's endowment that determines the provision of the IPG. Finally, equation (7b) indicates that when the asymmetry is rather moderate, it is in both countries' best interest to share the burden of the public good provision in the poor country. 
It is worth emphasizing that, when $\alpha>\theta$ and $\beta \in\left(\beta_{2}, \beta_{0}\right]$, the provision of the IPG and the levels of private consumptions are exactly the same as those given in equation (5). In other words, when $\alpha>\theta$ and $\beta \in\left(\beta_{2}, \beta_{0}\right]$, a two-stage IPG game with either income or in-kind transfers would yield the same equilibrium outcome.

\section{The Experiment}

The experiment consisted of seven sessions to study the neutrality theorem or the effectiveness of two different types of foreign aid. All sessions were conducted at the University of Canterbury, Christchurch, New Zealand, between March 2004 and March 2005. A total of 140 subjects were recruited from economics and mathematics introductory undergraduate courses. Some of the subjects may have participated in previous economics experiments, but none had any experience in the voluntary contribution mechanism and no subject participated in more than one session of the study. On average, a session lasted 120 minutes including initial instruction period and payment of subjects. The conversion rate differed between some sessions, but was always identical for all subjects within a given session. ${ }^{4}$ Subjects earned an average of NZ\$20.42. ${ }^{5}$ The experiment was computerized and used the Ztree software package (Fischbacher, 1999), which was developed at the Institute for Empirical Research in Economics at the University of Zurich.

Our core $2 \times 2$ design consisted of four treatments in which the treatment variables were aid scheme and endowment disparity. The two aid schemes were in-kind and income transfers. Aid transfers were considered as unconditional gifts. In other words, aid donors were not allowed to impose any conditions as to how aid recipients should respond to their assistance.

\footnotetext{
${ }^{4}$ The conversion rates ranged from $35-45$ francs per New Zealand dollar.

5 The adult minimum wage in New Zealand is $\$ 9.00 \mathrm{NZ}$ per hour.
} 
Furthermore, income transfers were fungible in the sense that aid received by the recipients can be allocated to either their personal consumption or public good in any way that they see fit. There were two endowment disparity conditions in which the two aid mechanisms were being tested: weak asymmetry (WA) and strong asymmetry (SA). The total endowment of each twoperson group always summed to 10 francs, but the individual endowments depended upon the treatment and subject type. ${ }^{6}$ Under WA, the rich were endowed with 6.25 francs and the poor were endowed with 3.75 francs. Under SA, the rich and the poor were endowed with 8.25 and 1.75 respectively. Table 1 provides the number of subjects participated in each of the four treatments: in-kind/WA, income/WA, in-kind/SA, and income/SA. ${ }^{7}$

[Table 1: About Here]

Using a repeated play, partners matching protocol, the participants were separated into two-person groups that remained constant for the entire session. ${ }^{8}$ Within each group, subjects were assigned a specific type, i.e. rich country or poor country. ${ }^{9}$ The computer terminals corresponding to particular groups and types were randomly distributed throughout the laboratory, and subjects were assigned to a group and type by their choice of terminal upon arrival for participation. Each participant was assigned an ID number and all interaction between group members took place through the computer terminal. Thus, all individual decisions remained anonymous.

\footnotetext{
${ }^{6}$ Francs were the currency used in the experiment.

${ }^{7}$ The number of participants in each session varied due to some recruited subjects not showing up for participation.

${ }^{8}$ As a robustness test for strategic behavior, we also conducted two sessions (in-kind vs. income transfers under SA) employing a stranger matching protocol in which the subjects were re-matched each period into new groups of two. We found that the results from these two sessions are consistent with those of the partner matching protocol. The data are not reported in the paper, but available upon request.

${ }^{9}$ Each subject in a two-person group represents a country in the theoretical model. To avoid framing effects in the experiment, we adopted the terms Type A and Type B for rich and poor countries respectively.
} 
Each session consisted of 30 periods. ${ }^{10}$ The total number of periods in a session was made common knowledge to the subjects as well as the fact that the rules of the game were identical for each period. At the beginning of each session, the experiment instructions were read aloud for the subjects, who followed along with their own copy of the instruction. The subjects were encouraged to ask questions relating to the rules and interface at any time. ${ }^{11}$

The procedures differ slightly between the two types of foreign aid. The income transfer mechanism consisted of a two-stage game. In the first stage, subjects had the opportunity to allocate some or all of their endowment to their counterpart group member. These decisions were made simultaneously by subjects clicking on the button that indicated the amount they wanted to transfer. ${ }^{12}$ Once all transfer decisions were made, the program progressed to the second stage. At the beginning of this stage, subjects were made aware of the amount of cash they had on hand, which consisted of their initial endowment minus their transfer to their group counterpart plus their counterpart's transfer to them. They had to simultaneously decide how much of this cash on hand to contribute only to their own public good and the remaining fraction is allocated to their personal consumption. Their decision was made by clicking on the button representing the integer amount that they wanted to contribute to their public good. The remaining fraction was automatically allocated to their personal consumption. In order to finalize their decisions for the period, subjects must click a DONE button. Subjects could change their decisions as many times as they like prior to hitting the DONE button.

\footnotetext{
${ }^{10}$ The subjects participated in an initial practice period, 0 , to familiarize themselves with the software and specific parameters of the experiment. The practice period did not count towards their earnings.

${ }^{11}$ Questions were asked privately to the experimenter in order to ensure that other subjects were not biased by potential normative statements/questions. If the question was beneficial to the group as a whole, the experimenter repeated the question and answer to the group.

${ }^{12}$ Cash transfers were restricted to integers.
} 
The in-kind transfer mechanism was very much like the income transfer, except that in the first stage, subjects transferred their endowment directly to their counterpart's public good. ${ }^{13}$ In the second stage, each subject was made aware of the contribution decisions of their counterpart to their own public good. They must then decide how much of the remaining portion of their endowment to contribute to their own public good and personal consumption respectively.

At the end of each period in all treatments, the computer displayed a summary screen of the decisions and earnings of both group members. In the treatments with income transfers, this consisted of both group members' transfer of endowment, contribution to their own public good, allocation to their own personal consumption and both group members' period earnings. In the treatments with in-kind transfers, the summary information consisted of both group members' contribution to each group project, sum of contributions to each project, their own allocation to personal consumption and both group members' period earnings.

The final two treatments, both/WA and both/SA, allowed for either an in-kind or income transfer in the first stage of the game by the same rules as in the treatments when each of them was offered exclusively. All other facets of these two treatments were exactly the same as the previous ones. The numbers of subjects participated in both/WA and both/SA are also given in Table 1.

For all treatments, subjects' payoff function was a discrete approximation of equation (1) with parameters $A=10$ and $\alpha=2 / 3$. The payoff matrices for the rich and the poor are given in Table 2.

\footnotetext{
${ }^{13}$ We imposed the same restriction as in Vicary and Sandler (2002) that subjects may contribute only up to half of their endowment to their counterpart's public good. This simply reduced the number of possible equilibria by eliminating half of the payoff matrix, but the optimal strategies were unaffected.
} 
[Table 2: About Here]

In section 2, we show that the Pareto perfect equilibrium of each of the two-stage games is unique. In addition, if $\alpha>\theta$ and $\beta \in\left(\beta_{2}, \beta_{0}\right]$, these two-stage games have the same set of equilibrium payoffs. Since the parameters used in our experiment under both WA and SA satisfied these conditions, in equilibrium $u_{P}^{*}=25$ and $u_{R}^{*}=27$, and the equilibrium path strategies were $\left\{s_{P}^{*}, s_{R}^{*}, c_{P}^{*}, c_{R}^{*}\right\}=\left\{h_{P}^{*}, h_{R}^{*}, c_{P}^{*}, c_{R}^{*}\right\}=\{0,1,1.75,2.25\}$ and $\{0,3,1.75,2.25\}$, respectively. In other words, the optimal strategy required the rich country to transfer 1 unit of its endowment to the poor under WA, but 3 units under SA. The equilibrium level of IPG was always equal to 3. Finally, because these payoffs, net transfers and contribution levels were unique, they were also unique at the Pareto perfect equilibria of finitely repeated games.

The results from our core $2 \times 2$ design are discussed in the following section.

\section{Results}

\subsection{Net Transfers}

The time series of the average net transfers from the rich to the poor under WA and SA are shown in Figure 1. The entire stacked column in each period represents the average gross transfers from the rich to the poor, and the white portion of it represents the average transfers from the poor to the rich. Hence, the black portion of each column illustrates the average net transfers from the rich to the poor. The first impression is that, regardless of the treatment of foreign aid, the average amount of net transfers in the first ten periods under either WA or SA was generally far away from the optimal level. This is particularly true under SA. It appears as though the subjects required a few periods to familiarize themselves with the complex decision 
environment. Nonetheless, from Figures 1(a) and 1(b), it is clear that average net transfers toward the end of the experiment under WA were extremely close to the equilibrium level. As for SA, Figures 1(c) and 1(d) indicate that net transfers eventually converged to the equilibrium only in the case of income transfers. Generally speaking, rich countries did not seem to transfer enough to their counterparts under SA.

[Figure 1: About Here]

Since we are more interested in equilibrium predictions and equilibrium behavior, we employ the data only from periods 11 to 30 in our data analysis throughout the rest of the paper. The statistical summary of several key variables from period 11 to period 30 is given in Table 3 . Results 1 and 2 in the following summarize the impact of the various treatments of foreign aid on the amount of net transfers under WA and SA, respectively.

[Table 3: About Here]

RESULT 1: On average, net transfers from the rich to the poor under WA are not significantly different from the Pareto perfect equilibrium level. Furthermore, the amount of foreign aid with in-kind transfers does not differ significantly from that with income transfers.

SUPPORT FOR RESULT 1: The average amount of in-kind transfers from the rich to the poor is 1.355 . The analogous number from to poor to the rich is 0.420 . With income transfers, the average amount of transfers is 1.542 from the rich to the poor and 0.647 from the poor to the 
rich. In sum, net transfers from periods 11 to 30 , as indicated in Table 3, are on average 0.935 with in-kind transfers, and 0.894 with income transfers. Without the assumption of normal distribution, we adopt a sign test that is distribution-free to see if the median of net transfers under each of these two aid treatments is significantly different from the equilibrium level. Taking each pair as one independent observation, neither medians under the two foreign aid treatments is significantly different from 1 at the $5 \%$ level ( $p$-value $=0.5078$ and 1.0000 for inkind and income transfers, respectively).

To see if the amount of foreign aid is different with the foreign aid treatments, we adopt the following panel data approach which allows us to take advantage of the cross-sectional and time-series variation in the data:

$$
N T_{i t}=\beta_{0}+\beta_{1} t+\beta_{2} D+u_{i t},
$$

where $N T_{i t}$ is group $i$ 's net transfers from the rich to the poor in period $t, D$ is a dummy variable that equals 1 for the in-kind treatment and 0 otherwise. The feasible GLS estimates are provided in Table 4. As shown in the second column of Table 4, the estimate of $\beta_{2}$ is not significantly different from zero, implying that the amount of net transfers with in-kind giving is not significantly different from that with income transfers.

[Table 4: About Here]

RESULT 2: Under SA, rich countries transfer significantly less than the optimal amount to their poor counterparts. The amount of foreign aid with in-kind transfers does not differ significantly from that with income transfers. 
SUPPORT FOR RESULT 2: The average amount of in-kind transfers from the rich to the poor is 2.727 . The analogous number from to poor to the rich is 0 . With income transfers, the average amount of transfers is 2.995 from the rich to the poor and 0.177 from the poor to the rich. In sum, net transfers between period 11 and period 30, as shown in Table 3, are on average 2.727 under in-kind, and 2.818 under income. Taking each pair as one independent observation, onesided sign tests show that the medians of net transfers under both treatments are significantly less than 3 at least at the $10 \%$ level $(p$-value $=0.0156$ and 0.0625 for in-kind and income transfers, respectively). The feasible GLS estimates for SA are shown in the third column of Table 4. The estimate of $\beta_{2}$ is not significantly different from zero. In other words, net transfers are not significantly different between the two foreign aid treatments.

\subsection{Provision of the IPG}

Figure 2 presents the times series of the average level of the IPG from periods 1 to 30 . Regardless of the aid treatment, Figure 2(a) shows that the IPG was constantly under provided under WA. This pattern persisted even to the last few periods of the experiment when foreign aid was on average at its optimal level.

[Figure 2: About Here]

RESULT 3: The IPG is under provided under WA. Nonetheless, the provision of the IPG is significantly higher with income transfers than with in-kind transfers. 
SUPPORT FOR RESULT 3: From periods 11 to 30, the average level of the IPG is 2.200 under in-kind, and 2.419 under income. Taking each pair as one independent observation, onesided sign tests show that both medians of the IPG provisions are significantly less than 3 ( $p$ value $=0.0020$ and 0.0000 for in-kind and income transfers, respectively).

The following panel-data regression model is used to investigate the influence of different aid treatments on the provision of the IPG, provided that the amount of foreign aid is controlled for:

$$
G_{i t}=\beta_{0}+\beta_{1} t+\beta_{2} D+\beta_{3} N T_{i t}+\beta_{4} N T_{i t}^{2}+u_{i t},
$$

where $G_{i t}$ is group $i$ 's provision level of the IPG in period $t . D$ and $N T$ are defined as in equation (8). The feasible GLS estimates are provided in the second column of Table 5. The estimate of $\beta_{2}$ being -0.322 implies that, after the amount of net transfers is controlled for, the IPG level under the in-kind transfer treatment is 0.322 units lower than that under the income transfer treatment each period, and this difference is statistically significant. $\hat{\beta}_{3}=0.581$ and $\hat{\beta}_{4}=-0.188$ imply that net transfers increase the level of the IPG at a decreasing rate.

[Table 5: About Here]

The under provision problem of the IPG is by no means a phenomenon that would occur only under WA. Figure 2(b) indicates that IPG was under provided under SA throughout the entire thirty periods, although the problem was perhaps less severe with in-kind transfers.

RESULT 4: The IPG is under provided under SA. The provision of the IPG is significantly higher with in-kind transfers than with income transfers. 
SUPPORT FOR RESULt 4: The average level of the IPG from period 11 to period 30 is 2.768 under the in-kind treatment, and 2.455 under income. As in WA, results from one-sided sign tests suggest that the medians of the IPG with both in-kind and income transfers are significantly less than 3 ( $p$-value $=0.0078$ and 0.0039 for in-kind and income transfers, respectively). Although the IPG is underprovided under both foreign aid treatments, the feasible GLS estimates of equation (10), shown in the third column of Table 5, suggest that the level of the IPG under in-kind is significantly higher than that under income. More specifically, the increment is about 0.310 units per period with in-kind transfers.

The result that the IPG is under provided even when foreign aid is at its optimal level should not surprise readers. It is consistent with, for example, Harrison and Hirshleifer (1989) who find that a public good of the weakest-link type is under provided when the contribution decisions are made simultaneously. In addition, previous studies have found that, with non-linear payoff functions such as the Cobb-Douglas utility function we adopted here, contributions to public goods tend to be below the Nash equilibrium prediction (Andreoni, 1993; Chan et al., 2002; and Cason et al., 2004). The importance of our findings, however, is that neutrality theorem is not supported by our data. The relative efficacy between in-kind and income transfers varies under different endowment conditions. Income transfers are more effective to advance the level of the IPG when the donor and the recipient are less asymmetric. In-kind transfers, on the contrary, appear to exhibit greater efficacy under the condition of strong asymmetry.

To search for an explanation to this observation, we divide the deviation of the IPG from its Pareto perfect equilibrium level into three components. The first component, defined as total 
investment into the two IPG projects minus $(2 \times \mathrm{IPG})$, captures some degree of the coordination failure between the donor and the recipient. In the case where there is no coordination failure, total investment in the Pareto perfect equilibrium should be 6 units of the aggregate endowment, equally divided between two countries. Suppose, for example, there are 3 units of the aggregate endowment being allocated to the rich country's public good, and 2 units to the poor country's. The provision level of the IPG in this case is $\min \{3,2\}=2$, and thus 1 unit of the resources $(3+2-2 \times 2=1)$ is wasted because of the coordination failure. For this reason, we call the first component "waste". The second and the third components concern the deviation of each country's consumption from its optimal level: the rich country's consumption deviation is defined as $c_{R}-2.25$, and the poor country's consumption deviation is defined as $c_{P}-1.75$. Note that the sum of these three components is:

$$
\begin{aligned}
\text { waste }+\left(c_{R}-2.25\right)+\left(c_{P}-1.75\right) & =\text { total investment }-2 \times \mathrm{IPG}+c_{R}+c_{P}-4 \\
& =10-2 \times \mathrm{IPG}-4 \\
& =6-2 \times \mathrm{IPG} \\
& =2 \times(3-\mathrm{IPG}) \\
& =2 \times \mathrm{IPG} \text { Dev. }
\end{aligned}
$$

RESULT 5: Income transfers have an exceptionally strong advantage of reducing coordination failure under WA. In-kind transfers can help reduce over-consumption, particularly on the part of poor countries under SA.

SUPPORT FOR RESULT 5: The regression analysis of equation (9) is conducted-with the dependent variable being substituted by waste, deviation of $c_{R}$, or deviation of $c_{P}$-to see how different foreign aid treatments affect factors that constitute the departure of the IPG from the Pareto perfect equilibrium. The feasible GLS estimates are summarized in Table 6. 
[Table 6: About Here]

Under WA, the amount of wasted resource with in-kind transfers is higher than that with income transfers by a significant amount of 0.323 per period, which suggests that income transfers are more effective in reducing coordination failure than in-kind transfers under WA. The departure of rich countries' consumption from the optimum is 0.220 higher under the inkind transfer treatment than under the income transfer treatment. The analogous number for the deviation of poor countries' consumption is 0.101 . Although income transfers also help reduce the departure of consumption on the part of the rich as well as the poor, the strength does not appear to be as strong as its influence on lessening coordination inefficiency.

Table 6 shows that the advantage of income transfers to reduce coordination failure completely disappears under SA. On the other hand, the consumption deviation of the rich and of the poor is 0.235 and 0.329 lower under the in-kind than under the income transfer treatment. Both are significant at the $5 \%$ level.

\subsection{Welfare}

Figure 3 shows the time series of the average utility of the rich, the poor, and also the global welfare under WA. It is obvious that both the rich and the poor reached higher utilities with income transfers after the first few periods of learning. The same time series for SA is presented in Figure 4. Under SA, it is in-kind transfers that made both parties better off. Also notice that the welfare of the rich from period 17 to period 30 under the in-kind transfer treatment was around 26 , implying only $3.7 \%$ of the efficiency loss for rich countries. 
[Figures 3 and 4: About Here]

In the following regression analysis, we define the welfare efficiency as the realized period payoff divided by the payoff at the Pareto perfect equilibrium. Results are summarized as the follows.

RESULT 6: Income transfers generate greater welfare for both the rich and the poor than in-kind transfers under WA. As a result, global welfare is higher with income transfers when the disparity in country size is relatively small.

SUPPORT FOR RESUlt 6: The feasible GLS estimates of equation (9) - the dependent variable is replaced with welfare efficiency-are given in Table 7. After we take the amount of foreign aid into consideration, in-kind transfers significantly reduce the welfare of the rich by $7.8 \%$ and the welfare of the poor by $9.6 \%$ from the income transfer treatment. On average, the difference, which is statistically significant, in the global welfare efficiency between these two aid schemes is $8.7 \%$ per period.

[Table 7: About Here]

RESULT 7: Under SA, in-kind transfers generate higher utilities for the rich and the poor than income transfers. The global welfare with in-kind transfers is thus higher than that with income transfers. 
SUPPORT FOR RESUlt 7: Table 7 also documents the feasible GLS estimates for SA. Given the amount of foreign aid, the welfare efficiencies of the rich and of the poor are $6.3 \%$ and 4.6\% higher with in-kind transfers than with income transfers. Consequently, the global welfare is approximately 5.5\% higher with in-kind transfers. All three estimates are significant at the 5\% level.

The above results indicate that Hypotheses 1 and 3 are not supported by our data. In other words, for either WA or SA endowment environment, outcomes with in-kind transfers are different from those with income transfers. Furthermore, variables such as the provision of the IPG and welfare efficiencies are all below our theoretical predictions. Finally, Results 8 and 9 in the following show that our Hypothesis 2 is rejected as well.

RESULT 8: Given either of the two foreign aid schemes, welfare of the rich under $S A$ is significantly higher than that under WA.

SUPPORT FOR RESULT 8: The mean utilities of the rich under our core four treatments, as mentioned before, are shown in Table 3. A Mann-Whitney ranksum test of the two different endowment conditions provides a $p$-value of 0.0000 for in-kind and a $p$-value of 0.0140 for income transfers. Therefore, we can reject the hypothesis at the 5\% level that the two distributions are the same given either type of the two transfer schemes. 
RESULT 9: Given in-kind transfers, welfare of the poor is significantly higher under SA than under WA. With income transfers, however, there is no significant difference in the poor countries' welfare between the two endowment conditions.

SUPPORT FOR RESUlt 9: Table 3 summarizes the mean utilities of the poor under different treatments. A Mann-Whitney ranksum test of the two different endowment conditions provides a $p$-value of 0.0000 for in-kind transfers and a $p$-value of 0.7375 for income transfers. Thus, we can reject the hypothesis that the two distributions are the same at the $5 \%$ level for inkind transfers but not for income transfers.

\section{Choice between Two Transfer Schemes}

Our results discussed above have shown that neutrality theorem is refuted, and that inkind and income transfers are more effective in enhancing welfare under SA and WA environment, respectively. We obtained these results by predetermining the type of foreign aid that subjects could implement. In a given session, there was no alternative option available for them to decide which of the two schemes was in fact more effective. If the subjects wanted to provide foreign aid to their counterpart, they were forced to employ the specific aid instrument that was given to them. In our last two treatments (both/WA and both/SA), we relaxed this constraint and allowed subjects to freely choose between either in-kind or income transfers. The specific research questions addressed in this section are: (1) When both foreign aid allocation mechanisms are made available simultaneously, will the rich eventually choose the type that was shown to be more effective when either mechanism was offered exclusively, i.e. income transfers under WA environment but in-kind transfers under SA environment? (2) If not, is it actually in 
rich countries' best interest to choose otherwise? ${ }^{14}$ The statistical summary of several key variables for the last twenty periods in both/WA and both/SA treatments is provided in Table 3 .

RESULT 10: When both income and in-kind transfers are available simultaneously under $W A$, the predominantly chosen aid scheme by the rich is in-kind transfer. ${ }^{15}$

SUPPORT FOR RESUlT 10: Figure 5(a) provides the type of aid that was adopted by the rich country in each group under WA over time. In total, there were 67 income transfers vs. 212 in-kind transfers from the rich to the poor for the entire course of the session. ${ }^{16}$ This pattern stays quite stable even for the last twenty periods, during which 42 income transfers vs. 143 inkind transfers were made by the rich.

[Figure 5(a): About Here]

Obviously, majority of the rich preferred to give in-kind. One conjecture for this outcome is that in-kind transfers ensure the foreign aid to be allocated to the IPG provision. In other words, with in-kind transfers, donors have a full control over the use of the aid. However, it may also be the case that the in-kind transfers are simply a more effective mechanism when both schemes are available simultaneously. To see if this is indeed the case, the following regression model, similar to equation (9), is used for the data analysis:

$$
Y_{i t}=\beta_{0}+\beta_{1} t+\beta_{2} D_{1 i t}+\beta_{3} D_{2}+\beta_{4} N T_{i t}+\beta_{5} N T_{i t}^{2}+u_{i t},
$$

\footnotetext{
${ }^{14}$ Note that, since subjects were not allowed to combine in-kind and income transfers in these two treatments, the game under both/WA and both/SA had only the two Pareto perfect equilibria described in Section 2.

${ }^{15}$ The predominantly chosen transfer mechanism by the poor is also in-kind transfer. In total, there were 34 income transfers and 128 in-kind transfers made by the poor throughout the entire thirty periods.

${ }^{16}$ There were a few periods in which some of the rich countries did not provide any foreign aid to their counterparts.
} 
where $Y_{i t}$ represents group $i$ 's IPG provision or welfare efficiencies in period $t . D_{1 i t}$ is a dummy variable that equals 1 if an in-kind transfer is made in period $t$ by the rich country in group $i$, and 0 if an income transfer is made instead. $D_{2}$ is a dummy variable that equals 1 for the groups that exercised income transfers less than $10 \%$ of their total plays (three times). ${ }^{17}$ The rationale behind adding this new dummy variable is that efficiency loss is presumably less severe when a group concentrates on learning and utilizing only one aid instrument. Therefore, we believe it is necessary to control for this particular effect in order to avoid a bias in the estimate of the impact of different aid schemes.

RESULT 11: When both income and in-kind transfers are available simultaneously under $W A$, the use of in-kind transfers as the predominant foreign aid scheme provides a lower provision of the IPG and lower overall welfare than if income transfers are used.

SUPPORT FOR RESULT 11: We employ the data only from periods 11 to 30 in our regression analysis. The feasible GLS estimates under WA are provided in Table 8 . The results are essentially the same as those when each of the two foreign aid schemes is offered exclusively under WA. The provision level of the IPG and the individual welfare efficiencies are significantly lower with in-kind transfers. As a consequence, the global welfare is significantly lower by approximately $6 \%$ per period when in-kind transfers are used by the rich.

[Table 8: About Here]

\footnotetext{
${ }^{17}$ They are group $\# 1, \# 5, \# 6$, and $\# 9$ under WA, and group \#1, \#2,\#3,\#6, \#7, and \#10 under SA.
} 
These results clearly suggest that most of the rich countries in our experiment did not choose the "right" tool to build up the provision of the IPG and to enhance welfare efficiencies. Being able to command the use of the foreign aid appears to dominate rich countries' decisions under WA.

RESULT 12: When both income and in-kind transfers are available simultaneously under SA, the predominantly chosen aid scheme by the rich is in-kind transfer.

SUPPORT FOR RESULT 12: Figure 5(b) provides the type of aid that was adopted by the rich country in each group under SA. Over the entire thirty periods of the experiment, the rich made a total of 264 in-kind transfers and 34 income transfers. Out of those 34 income transfers, 25 of them were made during the first ten periods. During the last ten periods, foreign aid was made entirely via in-kind transfers.

[Figure 5(b): About Here]

Apparently, rich countries under SA also preferred in-kind giving than income transfers. But this particular aid scheme is indeed the right choice for them to make: the provision of the IPG and the welfare efficiencies are all higher with in-kind transfers. This observation is stated as the following result. 
RESULT 13: When both income and in-kind transfers are available simultaneously under SA, the use of in-kind transfers as the predominant foreign aid scheme provides a higher provision of the IPG and higher overall level of welfare than if income transfers are used.

SUPPORT FOR RESULT 13: The feasible GLS estimates under SA are also summarized in Table 8 . The IPG provision is about 0.459 unit higher if an in-kind transfer is used in a given period. Both individual utilities are significantly higher with in-kind transfers. As a consequence, the global welfare is significantly higher by approximately $9 \%$ per period when in-kind transfers are used by the rich.

\section{Conclusion}

The level of foreign aid transferred between countries to finance international public goods has been steadily increasing over the last few decades both in terms of in-kind and income transfers. An interesting question with important policy implications is whether it matters which of these transfer mechanisms is implemented? In this study, we investigate whether in-kind and income transfers are equally effective in providing a weakest-link IPG, and if disparity in country size between donors and recipients plays a role in the effectiveness of either mechanism. We find that it certainly does matter, and that the relative efficacy of the transfer mechanisms varies with differences in the relative country size. More specifically, income transfers provide a higher level of the IPG and thus higher overall welfare level when the difference in country size is relatively small. On the other hand, when there is a large disparity in country size, in-kind transfers tend to generate a higher provision level of the IPG and higher accompanying global welfare. In sum, the neutrality theorem is refuted by our data. 
Why does it appear that income transfers perform better than in-kind transfers only in the situation where two countries are weakly asymmetric? Our results show that, under WA, income transfers could help reduce the amount of resources wasted due to coordination failure or mismatching behavior between the donor and the recipient. But, under SA, because the poor are so poor that their public goods need to be funded entirely by their rich counterparts, mismatching behavior is less likely to occur under such an endowment environment. Therefore, the advantage of income transfers that exists when countries are more alike completely vanishes once they are implemented under SA. Adding to the inefficiency of income transfers is that aid recipients have a tendency to consume a portion of the aid money that is intended to fund their public goods. The fungible nature of income transfers appears to have a particularly devastating effect on the public good provision when there are sharp differences between country sizes.

In addition to investigate the neutrality theorem, we also examine rich countries' preferences between in-kind and income transfers once both transfer schemes are made available for them to implement. We find that, regardless of the endowment condition, rich countries have a strong tendency to choose in-kind over income transfers even though it is not always in their interest to do so. This is particularly true when the donor's and the recipient's sizes are only weakly asymmetric. Being able to directly control the use of the foreign aid might have played some role in the rich countries' decision-making. 


\section{References}

Andreoni, J., "An Experimental Test of the Public-Goods Crowding-Out Hypothesis," American Economic Review, 1993, 83, 1317-1327.

Camerer, F. Colin, Behavioral Game Theory: Experiments in Strategic Interaction, Princeton University Press, 2003.

Cason T. N., T. Saijo, T. Yamato, and K. Yokotani, "Non-excludable Public Good Experiments," Games and Economic Behavior, 2004, 49, 81-102.

Chan, K., R. Godby, S. Mestelman, R. A. Muller, "Crowding Out Voluntary Contributions to Public Goods," Journal of Economic Behavior and Organization, 2002, 48, 305-317.

Fischbacher, U., "z-Tree-Toolbox for Readymade Economic Experiments," IEW Working Paper 21, University of Zurich.

Harrison, G. W. and J. Hirshleifer, "An Experimental Evaluation of Weakest Link/Best Shot Models of Public Goods,” Journal of Political Economy, 1989, 97(1), 201-225.

Hirshleifer, J., "From Weakest-Link to Best-Shot: The Voluntary Provision of Public Goods," Public Choice, 1983, 41, 371-386.

Jayaraman, R. and R. Kanbur, "International Public Goods and the Case for Foreign Aid," in I. Kaul, I. Grunberg, and M. Stern, eds., Global Public Goods: International Cooperation in the $21^{\text {st }}$ Century, Oxford University Press, 1999, 418-435.

OECD, “Analysis of Aid in Support of HIV/AIDS Control, 2000-2002,” 2004.

Vicary, S, “Transfers and the Weakest-Link: An Extension of Hirshleifer's Analysis," Journal of Public Economics, 1990, 43, 375-394.

Vicary, S. and T. Sandler, "Weakest-Link Public Goods: Giving In-Kind or Transferring Money," European Economic Review, 2002, 46, 1501-1520.

Warr, P., "The Private Provision of a Public Good is Independent of the Distribution of Income," Economics Letters, 1983, 13, 207-211.

World Bank, "Effective Use of Development Finance for International Public Goods," 2001. 
Table 1: Summary of the Treatments and Number of Subjects

\begin{tabular}{|c|c|c|c|}
\hline & & \multicolumn{2}{|c|}{ Endowment Disparity } \\
\hline & & $\begin{array}{c}\text { Weak Asymmetry } \\
(6.25 \text { vs. } 3.75)\end{array}$ & $\begin{array}{c}\text { Strong Asymmetry } \\
(8.25 \text { vs. } 1.75)\end{array}$ \\
\hline \multirow{3}{*}{ Type of Aid } & In-kind Transfers & 20 & 22 \\
\hline & Income Transfers & 36 & 22 \\
\hline & $\begin{array}{c}\text { Both Options } \\
\text { Available }\end{array}$ & 20 & 20 \\
\hline
\end{tabular}


Table 2a: Payoff Matrix for the Rich

\begin{tabular}{|c|c|c|c|c|c|c|c|c|c|c|}
\hline \multicolumn{2}{|c|}{} & \multicolumn{10}{|c|}{$\boldsymbol{c}_{\boldsymbol{R}}$} \\
\cline { 2 - 13 } & $\mathbf{0 . 2 5}$ & $\mathbf{1 . 2 5}$ & $\mathbf{2 . 2 5}$ & 3.25 & 4.25 & $\mathbf{5 . 2 5}$ & $\mathbf{6 . 2 5}$ & $\mathbf{7 . 2 5}$ & $\mathbf{8 . 2 5}$ \\
\hline \multirow{4}{*}{$\boldsymbol{G}$} & $\boldsymbol{0}$ & 0 & 0 & 0 & 0 & 0 & 0 & 0 & 0 & 0 \\
\cline { 2 - 13 } & $\boldsymbol{1}$ & 6 & 10 & 13 & 14 & 16 & 17 & 18 & 19 & \\
\cline { 2 - 13 } & $\boldsymbol{2}$ & 10 & 17 & 20 & 23 & 25 & 27 & & & \\
\cline { 2 - 12 } & 3 & 13 & 22 & 27 & 30 & & & & & \\
\cline { 2 - 12 } & 4 & 15 & 27 & & & & & & & \\
\hline
\end{tabular}

Table 2b: Payoff Matrix for the Poor

\begin{tabular}{|c|c|c|c|c|c|c|c|c|c|c|}
\hline \multicolumn{2}{|c|}{} & \multicolumn{10}{|c|}{$\boldsymbol{c}_{\boldsymbol{P}}$} \\
\cline { 3 - 13 } & $\mathbf{0 . 7 5}$ & $\mathbf{1 . 7 5}$ & $\mathbf{2 . 7 5}$ & 3.75 & $\mathbf{4 . 7 5}$ & $\mathbf{5 . 7 5}$ & $\mathbf{6 . 7 5}$ & 7.75 & $\mathbf{8 . 7 5}$ \\
\hline \multirow{4}{*}{$\boldsymbol{G}$} & $\boldsymbol{0}$ & 0 & 0 & 0 & 0 & 0 & 0 & 0 & 0 & 0 \\
\cline { 2 - 13 } & $\boldsymbol{1}$ & 9 & 12 & 14 & 15 & 16 & 17 & 18 & 19 & \\
\cline { 2 - 12 } & $\boldsymbol{2}$ & 14 & 19 & 22 & 24 & 26 & 28 & & & \\
\cline { 2 - 12 } & 3 & 18 & 25 & 29 & 32 & & & & & \\
\cline { 2 - 11 } & 4 & 22 & 30 & & & & & & & \\
\hline
\end{tabular}


Table 3: Statistical Summary of Key Variables from Periods 11 to 30

\begin{tabular}{|c|c|c|c|c|c|c|}
\hline \multirow{2}{*}{} & \multicolumn{3}{|c|}{ WA } & \multicolumn{3}{c|}{$\begin{array}{c}\text { SA } \\
(6.25 \text { vs. 3.75) }\end{array}$} \\
\cline { 2 - 7 } & $\begin{array}{c}\text { In-kind } \\
\text { Transfers }\end{array}$ & $\begin{array}{c}\text { Income } \\
\text { Transfers }\end{array}$ & $\begin{array}{c}\text { Both } \\
\text { Options } \\
\text { Available }\end{array}$ & $\begin{array}{c}\text { In-kind } \\
\text { Transfers }\end{array}$ & $\begin{array}{c}\text { Income } \\
\text { Transfers }\end{array}$ & $\begin{array}{c}\text { Both } \\
\text { Options } \\
\text { Available }\end{array}$ \\
\hline $\begin{array}{c}\text { Net } \\
\text { Transfers }\end{array}$ & 0.935 & 0.894 & 0.905 & 2.727 & 2.818 & 2.920 \\
$(0.751)$ & $(1.029)$ & $(0.677)$ & $(0.647)$ & $(0.784)$ & $(0.405)$ \\
\hline$G$ & 2.200 & 2.419 & 2.360 & 2.768 & 2.455 & 2.890 \\
& $(0.839)$ & $(0.715)$ & $(0.750)$ & $(0.537)$ & $(0.784)$ & $(0.423)$ \\
\hline \multirow{2}{*}{$u_{R}$} & 22.070 & 23.500 & 23.090 & 25.727 & 23.805 & 26.365 \\
& $(6.089)$ & $(4.938)$ & $(5.479)$ & $(3.589)$ & $(5.660)$ & $(2.909)$ \\
\hline \multirow{2}{*}{$u_{P}$} & 20.320 & 21.992 & 21.485 & 23.055 & 22.005 & 24.240 \\
& $(6.006)$ & $(5.161)$ & $(5.236)$ & $(4.333)$ & $(5.222)$ & $(3.081)$ \\
\hline \multirow{2}{*}{ Obs. } & 200 & 360 & 200 & 220 & 220 & 200 \\
\hline
\end{tabular}

Standard deviations are in parentheses. 
Table 4: The Feasible GLS Estimates of Net Transfers from the Rich to the Poor

\begin{tabular}{|l|c|c|}
\hline & WA & SA \\
& $(6.25$ vs. 3.75) & $(8.25$ vs. 1.75) \\
\hline Constant & $0.828^{* * *}$ & $2.693^{* * *}$ \\
& $(0.087)$ & $(0.078)$ \\
\hline Period & 0.006 & $0.012^{* * *}$ \\
& $(0.007)$ & $(0.006)$ \\
\hline Dummy for In-Kind Treatment & 0.041 & -0.091 \\
& $(0.083)$ & $(0.068)$ \\
\hline Number of Groups & 28 & 22 \\
\hline Number of Observations & 560 & 440 \\
\hline
\end{tabular}

***: significant at the 5\% level. Standard errors are in parentheses.

Table 5: The Feasible GLS Estimates of the IPG Level

\begin{tabular}{|l|c|c|}
\hline & WA & SA \\
& $(6.25 \mathrm{vs.} \mathrm{3.75)}$ & $(8.25 \mathrm{vs.} \mathrm{1.75)}$ \\
\hline Constant & $2.178^{* * *}$ & 0.022 \\
& $(0.065)$ & $(0.136)$ \\
\hline Period & 0.007 & 0.006 \\
& $(0.005)$ & $(0.004)$ \\
\hline Dummy for In-Kind Treatment & $-0.322^{* * *}$ & $0.310^{* * *}$ \\
& $(0.057)$ & $(0.048)$ \\
\hline Net Transfers & $0.581^{* * *}$ & $1.413^{* * *}$ \\
& $(0.041)$ & $(0.086)$ \\
\hline Net Transfers) $^{2}$ & $-0.188^{* * *}$ & $-0.189^{* * *}$ \\
& $(0.014)$ & $(0.016)$ \\
\hline Number of Groups & 28 & 22 \\
\hline Number of Observations & 560 & 440 \\
\hline
\end{tabular}

***: significant at the 5\% level. Standard errors are in parentheses. 
Table 6: Components of the Deviation of the IPG

\begin{tabular}{|c|c|c|c|c|c|c|}
\hline & \multicolumn{3}{|c|}{$\begin{array}{c}\text { WA } \\
(6.25 \text { vs. } 3.75) \\
\end{array}$} & \multicolumn{3}{|c|}{$\begin{array}{c}\text { SA } \\
(8.25 \text { vs. } 1.75) \\
\end{array}$} \\
\hline & waste & $c_{R}$ dev. & $c_{P}$ dev. & waste & $c_{R}$ dev. & $c_{P}$ dev. \\
\hline Constant & $\begin{array}{c}0.384 * * * \\
(0.067)\end{array}$ & $\begin{array}{c}1.381 * * * \\
(0.060)\end{array}$ & $\begin{array}{c}-0.120 * * \\
(0.067)\end{array}$ & $\begin{array}{c}2.703 * * * \\
(0.161)\end{array}$ & $\begin{array}{c}3.378^{* * * *} \\
(0.155)\end{array}$ & $\begin{array}{l}-0.126 \\
(0.123)\end{array}$ \\
\hline Period & $\begin{array}{l}-0.007 \\
(0.005)\end{array}$ & $\begin{array}{c}0.001 \\
(0.004)\end{array}$ & $\begin{array}{l}-0.007 \\
(0.005)\end{array}$ & $\begin{array}{l}-0.006 \\
(0.005)\end{array}$ & $\begin{array}{l}-0.004 \\
(0.005)\end{array}$ & $\begin{array}{l}-0.002 \\
(0.004)\end{array}$ \\
\hline $\begin{array}{l}\text { Dummy for In- } \\
\text { Kind Treatment }\end{array}$ & $\begin{array}{c}0.323 * * * \\
(0.060)\end{array}$ & $\begin{array}{c}0.220 * * * \\
(0.053)\end{array}$ & $\begin{array}{l}0.101 * * \\
(0.059)\end{array}$ & $\begin{array}{l}-0.057 \\
(0.057)\end{array}$ & $\begin{array}{c}-0.235^{* * *} \\
(0.055)\end{array}$ & $\begin{array}{c}-0.329 * * * \\
(0.044)\end{array}$ \\
\hline Net Transfers & $\begin{array}{c}-0.245^{* * * *} \\
(0.042)\end{array}$ & $\begin{array}{c}-1.295^{* * * *} \\
(0.038)\end{array}$ & $\begin{array}{c}0.376^{* * * *} \\
(0.042)\end{array}$ & $\begin{array}{c}-1.325^{* * * *} \\
(0.102)\end{array}$ & $\begin{array}{c}-1.229 * * * \\
(0.099)\end{array}$ & $\begin{array}{c}-0.273^{* * * *} \\
(0.078)\end{array}$ \\
\hline (Net Transfers) $^{2}$ & $\begin{array}{c}0.135^{* * *} \\
(0.015)\end{array}$ & $\begin{array}{c}0.141 * * * \\
(0.014)\end{array}$ & $\begin{array}{c}0.101 * * * \\
(0.015)\end{array}$ & $\begin{array}{c}0.169^{* * *} \\
(0.019)\end{array}$ & $\begin{array}{c}0.064 * * * \\
(0.018)\end{array}$ & $\begin{array}{c}0.144^{* * * *} \\
(0.014)\end{array}$ \\
\hline $\begin{array}{l}\text { Number of } \\
\text { Groups }\end{array}$ & 28 & 28 & 28 & 22 & 22 & 22 \\
\hline $\begin{array}{l}\text { Number of } \\
\text { Observations }\end{array}$ & 560 & 560 & 560 & 440 & 440 & 440 \\
\hline
\end{tabular}

***, **: significant at the $5 \%$ and $10 \%$ levels, respectively. Standard errors are in parentheses. 
Table 7: The Feasible GLS Estimates of Individual Welfare and Global Welfare

\begin{tabular}{|c|c|c|c|c|c|c|}
\hline & \multicolumn{3}{|c|}{$\begin{array}{c}\text { WA } \\
(6.25 \text { vs. } 3.75)\end{array}$} & \multicolumn{3}{|c|}{$\begin{array}{c}\text { SA } \\
(8.25 \text { vs. } 1.75)\end{array}$} \\
\hline & $\begin{array}{c}\text { Rich } \\
\text { Welfare } \\
\text { Efficiency }\end{array}$ & $\begin{array}{c}\text { Poor } \\
\text { Welfare } \\
\text { Efficiency }\end{array}$ & $\begin{array}{c}\text { Global } \\
\text { Welfare } \\
\text { Efficiency }\end{array}$ & $\begin{array}{c}\text { Rich } \\
\text { Welfare } \\
\text { Efficiency }\end{array}$ & $\begin{array}{c}\text { Poor } \\
\text { Welfare } \\
\text { Efficiency }\end{array}$ & $\begin{array}{c}\text { Global } \\
\text { Welfare } \\
\text { Efficiency }\end{array}$ \\
\hline Constant & $\begin{array}{c}0.876^{* * *} \\
(0.017)\end{array}$ & $\begin{array}{c}0.763 * * * \\
(0.016)\end{array}$ & $\begin{array}{c}0.822 * * * \\
(0.016)\end{array}$ & $\begin{array}{c}0.396^{* * * *} \\
(0.040)\end{array}$ & $\begin{array}{l}0.119 * * * \\
(0.035)\end{array}$ & $\begin{array}{c}0.263 * * * \\
(0.036)\end{array}$ \\
\hline Period & $\begin{array}{c}0.003 * * * \\
(0.001)\end{array}$ & $\begin{array}{c}0.001 \\
(0.001)\end{array}$ & $\begin{array}{c}0.002 \\
(0.001)\end{array}$ & $\begin{array}{c}0.001 \\
(0.001)\end{array}$ & $\begin{array}{c}0.002 \\
(0.001)\end{array}$ & $\begin{array}{c}0.001 \\
(0.001)\end{array}$ \\
\hline $\begin{array}{l}\text { Dummy for In- } \\
\text { Kind Treatment }\end{array}$ & $\begin{array}{c}-0.078 * * * \\
(0.015)\end{array}$ & $\begin{array}{c}-0.096 * * * \\
(0.014)\end{array}$ & $\begin{array}{c}-0.087 * * * \\
(0.014)\end{array}$ & $\begin{array}{c}0.063 * * * \\
(0.014)\end{array}$ & $\begin{array}{c}0.046 * * * \\
(0.012)\end{array}$ & $\begin{array}{c}0.055^{* * *} * \\
(0.013)\end{array}$ \\
\hline Net Transfers & $\begin{array}{c}0.071 * * * \\
(0.011)\end{array}$ & $\begin{array}{c}0.220 * * * \\
(0.010)\end{array}$ & $\begin{array}{c}0.143 * * * \\
(0.010)\end{array}$ & $\begin{array}{c}0.336 * * * \\
(0.025)\end{array}$ & $\begin{array}{c}0.410 * * * \\
(0.022)\end{array}$ & $\begin{array}{c}0.372 * * * \\
(0.023)\end{array}$ \\
\hline (Net Transfers) $^{2}$ & $\begin{array}{c}-0.052 * * * \\
(0.004)\end{array}$ & $\begin{array}{c}-0.048 * * * \\
(0.004)\end{array}$ & $\begin{array}{c}-0.050 * * * \\
(0.004)\end{array}$ & $\begin{array}{c}-0.055 * * * \\
(0.005)\end{array}$ & $\begin{array}{c}-0.048 * * * \\
(0.004)\end{array}$ & $\begin{array}{c}-0.052 * * * \\
(0.004)\end{array}$ \\
\hline $\begin{array}{l}\text { Number of } \\
\text { Groups }\end{array}$ & 28 & 28 & 28 & 22 & 22 & 22 \\
\hline $\begin{array}{l}\text { Number of } \\
\text { Observations }\end{array}$ & 560 & 560 & 560 & 440 & 440 & 440 \\
\hline
\end{tabular}

***: significant at the 5\% level. Standard errors are in parentheses. 
Table 8: The Feasible GLS Estimates When Both Foreign Aid Schemes Are Available Simultaneously

\begin{tabular}{|c|c|c|c|c|c|c|c|c|}
\hline & \multicolumn{4}{|c|}{$\begin{array}{c}\text { WA } \\
(6.25 \text { vs. } 3.75) \\
\end{array}$} & \multicolumn{4}{|c|}{$\begin{array}{c}\text { SA } \\
(8.25 \text { vs. } 1.75) \\
\end{array}$} \\
\hline & IPG & $\begin{array}{c}\text { Rich } \\
\text { Welfare } \\
\text { Efficiency } \\
\end{array}$ & $\begin{array}{c}\text { Poor } \\
\text { Welfare } \\
\text { Efficiency } \\
\end{array}$ & $\begin{array}{c}\text { Global } \\
\text { Welfare } \\
\text { Efficiency } \\
\end{array}$ & IPG & $\begin{array}{c}\text { Rich } \\
\text { Welfare } \\
\text { Efficiency }\end{array}$ & $\begin{array}{c}\text { Poor } \\
\text { Welfare } \\
\text { Efficiency } \\
\end{array}$ & $\begin{array}{c}\text { Global } \\
\text { Welfare } \\
\text { Efficiency } \\
\end{array}$ \\
\hline Constant & $\begin{array}{c}2.041 * * * \\
(0.136)\end{array}$ & $\begin{array}{c}0.830 * * * \\
(0.028)\end{array}$ & $\begin{array}{c}0.749 * * * \\
(0.030)\end{array}$ & $\begin{array}{c}0.791 * * * \\
(0.027)\end{array}$ & $\begin{array}{l}-0.498 \\
(0.330)\end{array}$ & $\begin{array}{c}0.319 * * * \\
(0.103)\end{array}$ & $\begin{array}{c}0.131 \\
(0.101)\end{array}$ & $\begin{array}{c}0.228 * * * \\
(0.100)\end{array}$ \\
\hline Period & $\begin{array}{r}0.001 \\
(0.007) \\
\end{array}$ & $\begin{array}{r}0.001 \\
(0.001) \\
\end{array}$ & $\begin{array}{r}0.001 \\
(0.001) \\
\end{array}$ & $\begin{array}{r}0.001 \\
(0.001) \\
\end{array}$ & $\begin{array}{l}-0.001 \\
(0.003) \\
\end{array}$ & $\begin{array}{c}-0.00003 \\
(0.001) \\
\end{array}$ & $\begin{array}{l}0.00001 \\
(0.001) \\
\end{array}$ & $\begin{array}{c}-0.00001 \\
(0.001) \\
\end{array}$ \\
\hline $\begin{array}{l}\text { Dummy for } \\
\text { In-Kind Transfers }\end{array}$ & $\begin{array}{c}-0.243 * * * \\
(0.109)\end{array}$ & $\begin{array}{c}-0.050 * * * \\
(0.022)\end{array}$ & $\begin{array}{c}-0.071 * * * \\
(0.024)\end{array}$ & $\begin{array}{c}-0.060 * * * \\
(0.022)\end{array}$ & $\begin{array}{c}0.459 * * * \\
(0.105)\end{array}$ & $\begin{array}{c}0.085 * * * \\
(0.033)\end{array}$ & $\begin{array}{c}0.101 * * * \\
(0.032)\end{array}$ & $\begin{array}{c}0.093 * * * \\
(0.032)\end{array}$ \\
\hline $\begin{array}{l}\text { Dummy for Not } \\
\text { Using Different } \\
\text { Aid Options }\end{array}$ & $\begin{array}{c}0.356 * * * \\
(0.097)\end{array}$ & $\begin{array}{c}0.081 * * * \\
(0.020)\end{array}$ & $\begin{array}{c}0.093 * * * \\
(0.022)\end{array}$ & $\begin{array}{c}0.087 * * * \\
(0.019)\end{array}$ & $\begin{array}{l}-0.004 \\
(0.039)\end{array}$ & $\begin{array}{l}-0.004 \\
(0.012)\end{array}$ & $\begin{array}{l}-0.008 \\
(0.012)\end{array}$ & $\begin{array}{l}-0.006 \\
(0.012)\end{array}$ \\
\hline Net Transfers & $\begin{array}{c}1.127 * * * \\
(0.173) \\
\end{array}$ & $\begin{array}{c}0.242 * * * \\
(0.035) \\
\end{array}$ & $\begin{array}{c}0.263 * * * \\
(0.038) \\
\end{array}$ & $\begin{array}{c}0.252 * * * \\
(0.034) \\
\end{array}$ & $\begin{array}{c}1.540 * * * \\
(0.321) \\
\end{array}$ & $\begin{array}{c}0.389 * * * \\
(0.100) \\
\end{array}$ & $\begin{array}{c}0.329 * * * \\
(0.099) \\
\end{array}$ & $\begin{array}{c}0.360 * * * \\
(0.097) \\
\end{array}$ \\
\hline$(\text { Net Transfers })^{2}$ & $\begin{array}{c}-0.524 * * * \\
(0.075)\end{array}$ & $\begin{array}{c}-0.147 * * * \\
(0.015)\end{array}$ & $\begin{array}{c}-0.081 * * * \\
(0.017) \\
\end{array}$ & $\begin{array}{c}-0.115 * * * \\
(0.015) \\
\end{array}$ & $\begin{array}{c}-0.178 * * * \\
(0.068) \\
\end{array}$ & $\begin{array}{c}-0.064 * * * \\
(0.021) \\
\end{array}$ & $\begin{array}{l}-0.025 \\
(0.021) \\
\end{array}$ & $\begin{array}{c}-0.045^{* * *} \\
(0.020)\end{array}$ \\
\hline $\begin{array}{l}\text { Number of } \\
\text { Observations }\end{array}$ & 185 & 185 & 185 & 185 & 199 & 199 & 199 & 199 \\
\hline
\end{tabular}

***: significant at the $5 \%$ level. Standard errors are in parentheses. 
Figure 1: Time Series of the Average Net Transfers from the Rich to the Poor (a) In-kind/WA

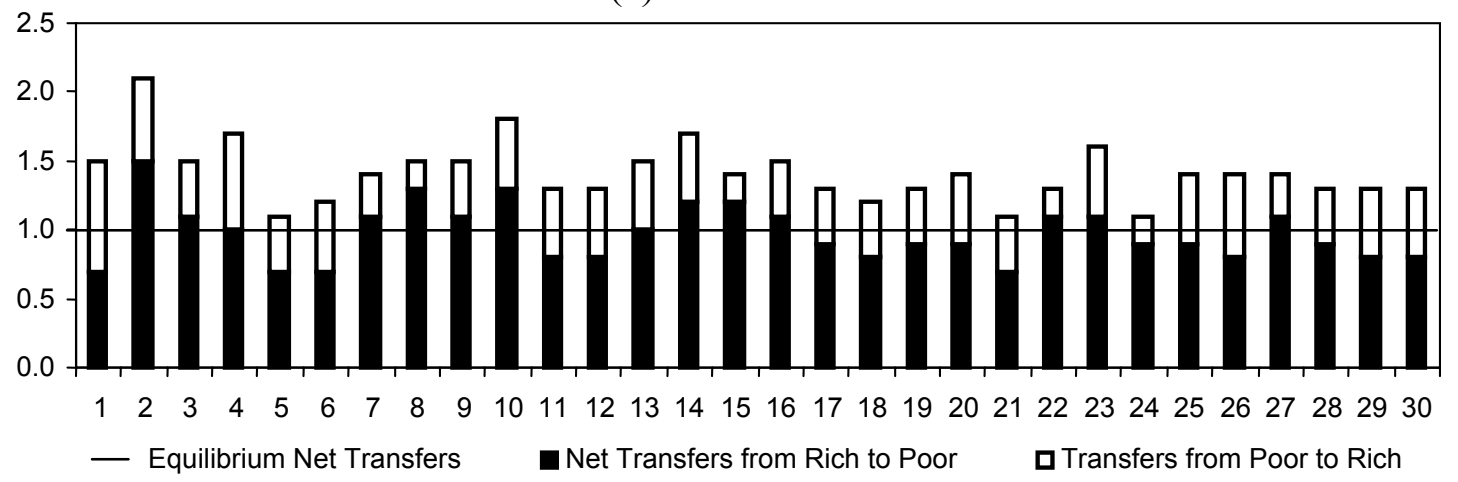

(b) Income/WA

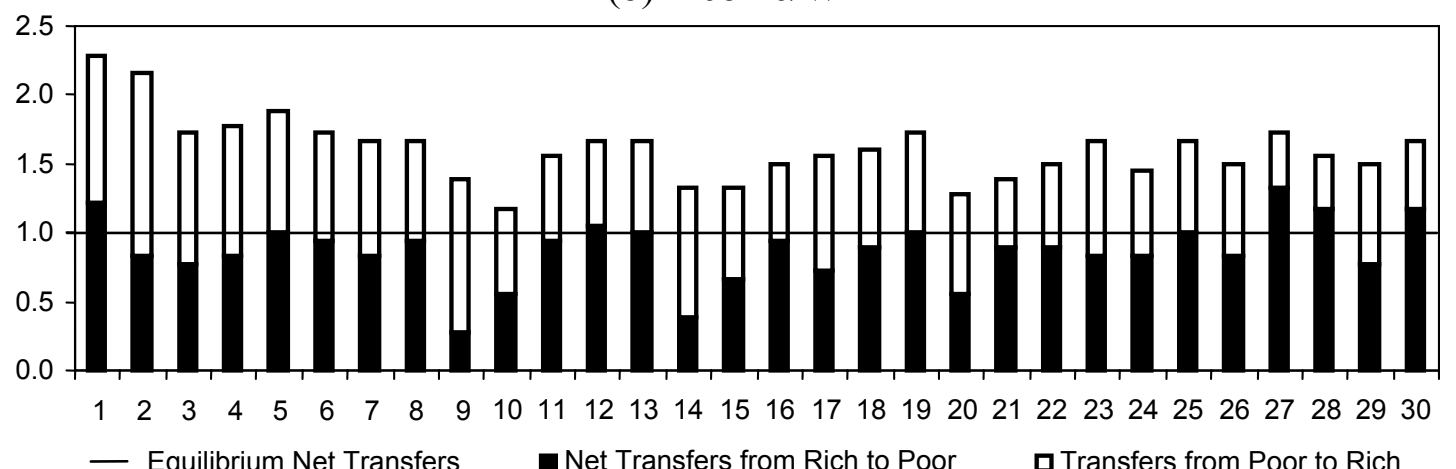

(c) In-kind/SA

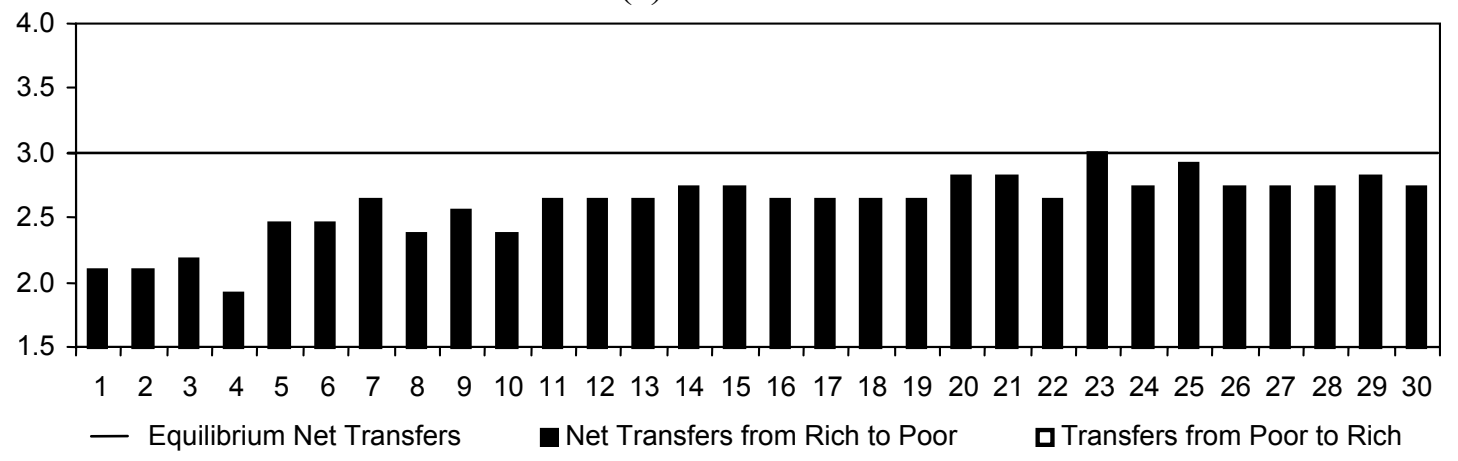

(d) Income/SA

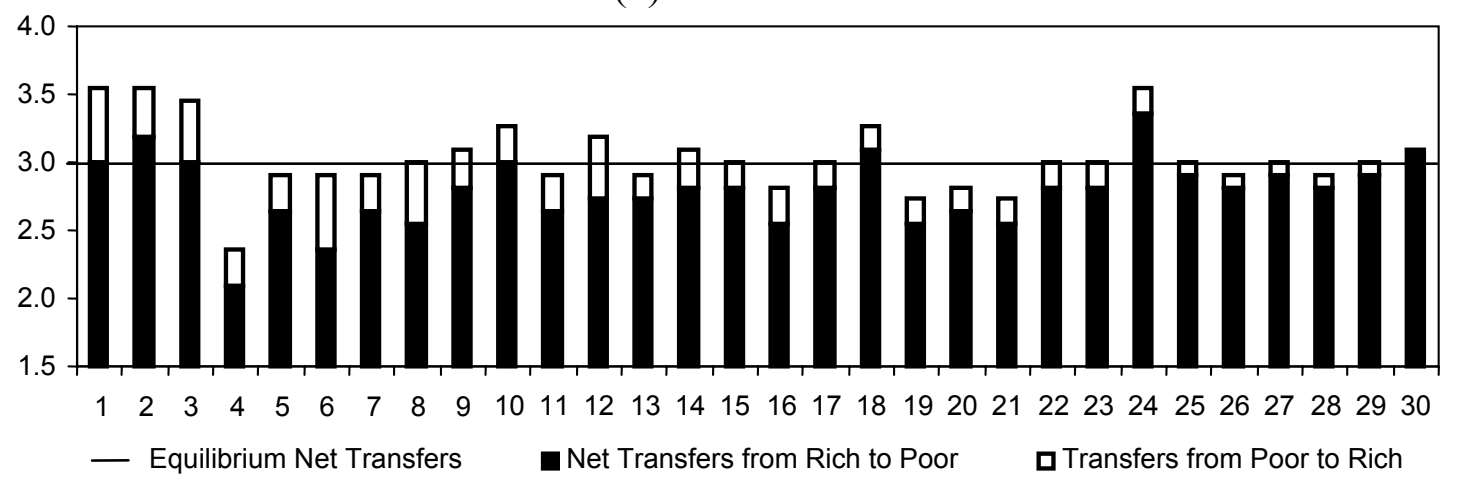


Figure 2: Time Series of the Average IPG Level

(a) WA

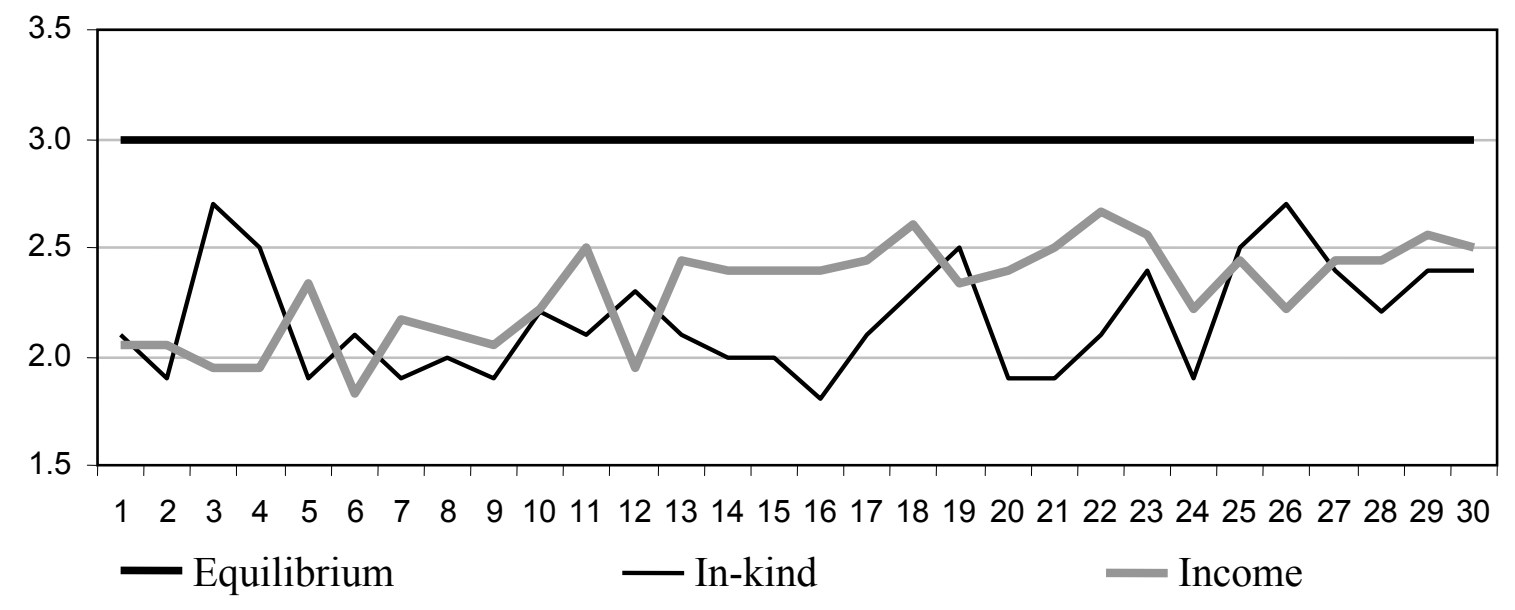

(b) $\mathrm{SA}$

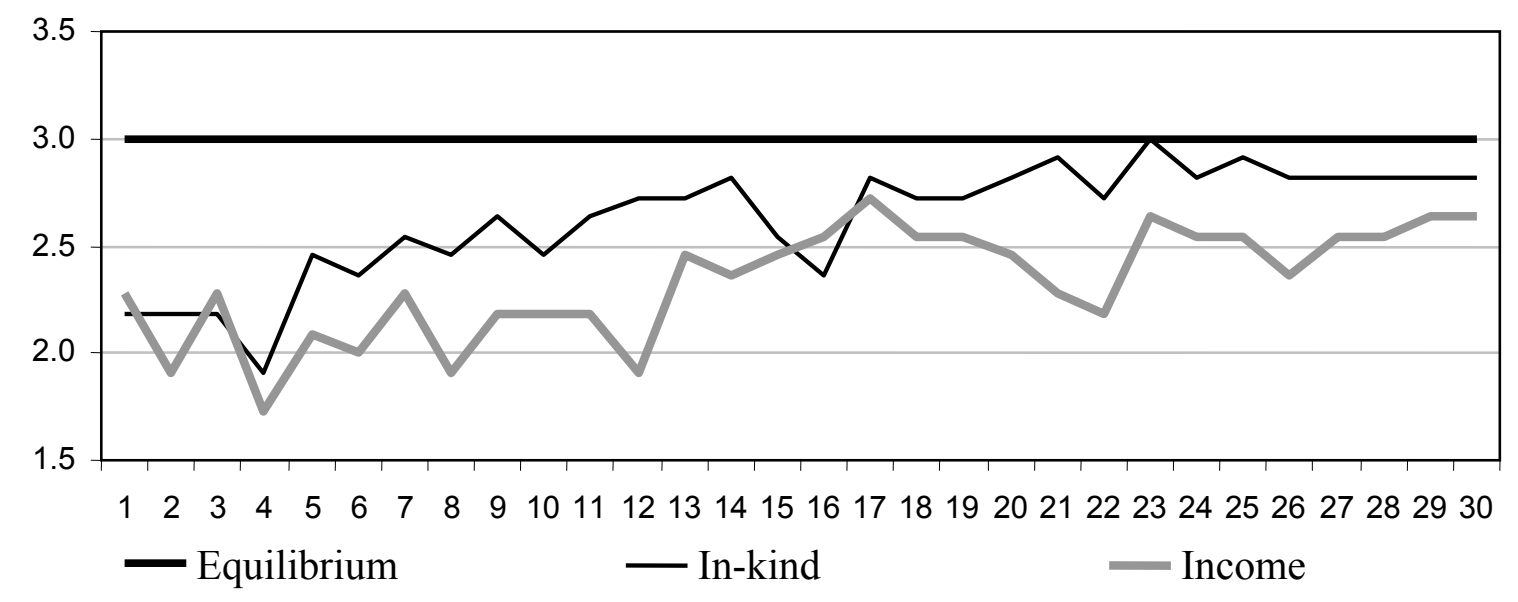


Figure 3: Time Series of the Average Payoffs under WA

(a) Rich Country

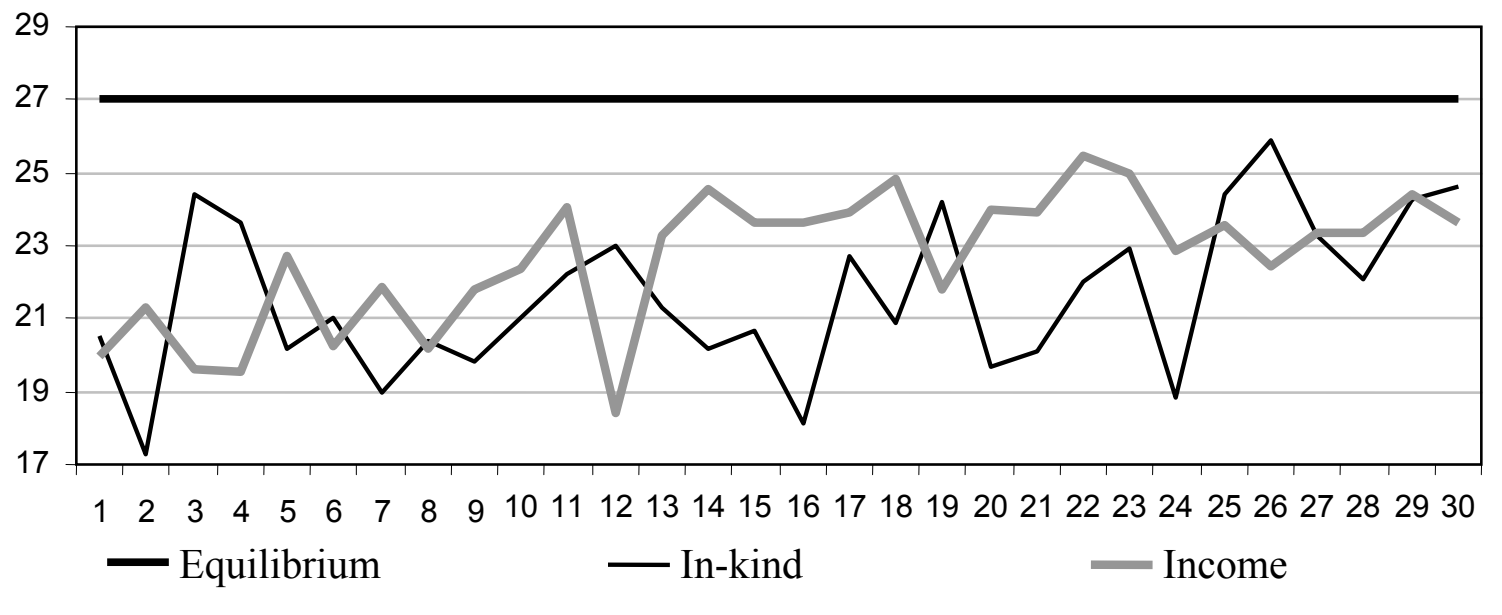

(b) Poor Country

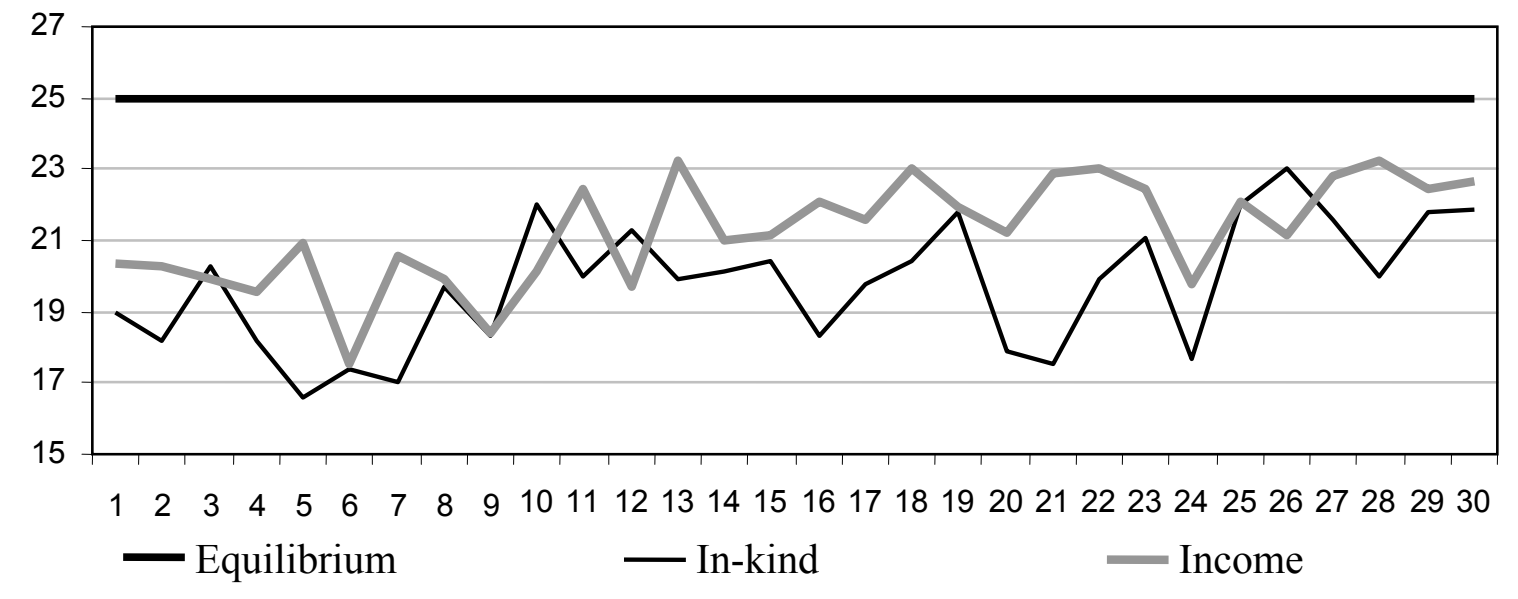

(c) Global Welfare

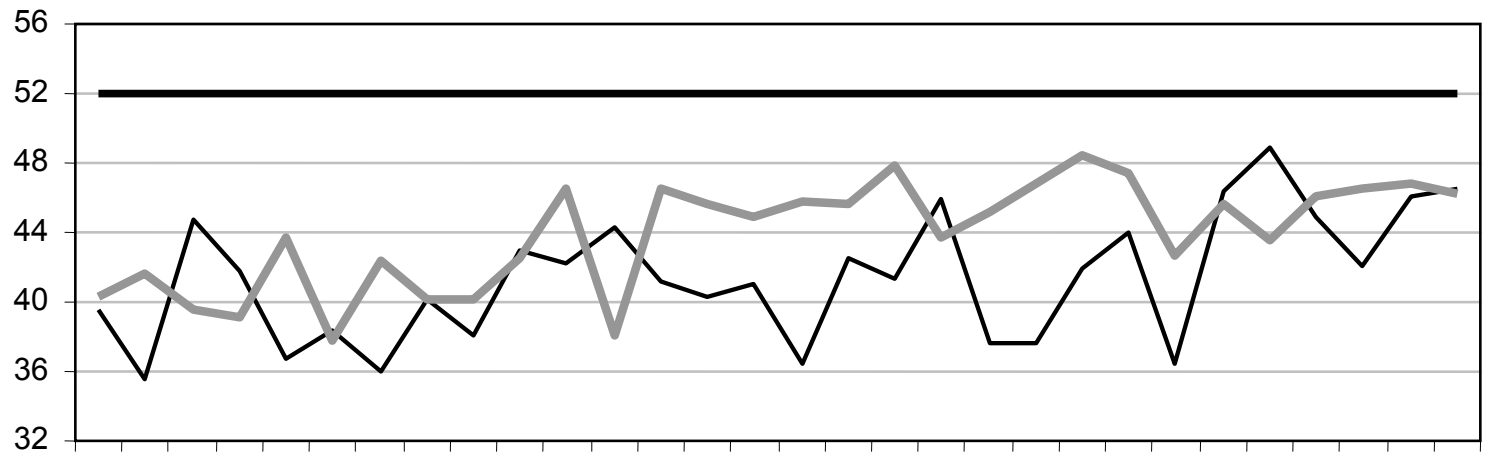

$1 \quad 2 \quad 3 \quad 4 \quad 5 \quad 6 \quad 7 \quad 8 \quad 9101112131415161718192021222324252627282930$

- Equilibrium In-kind Income 
Figure 4: Time Series of the Average Payoffs under SA

(a) Rich Country

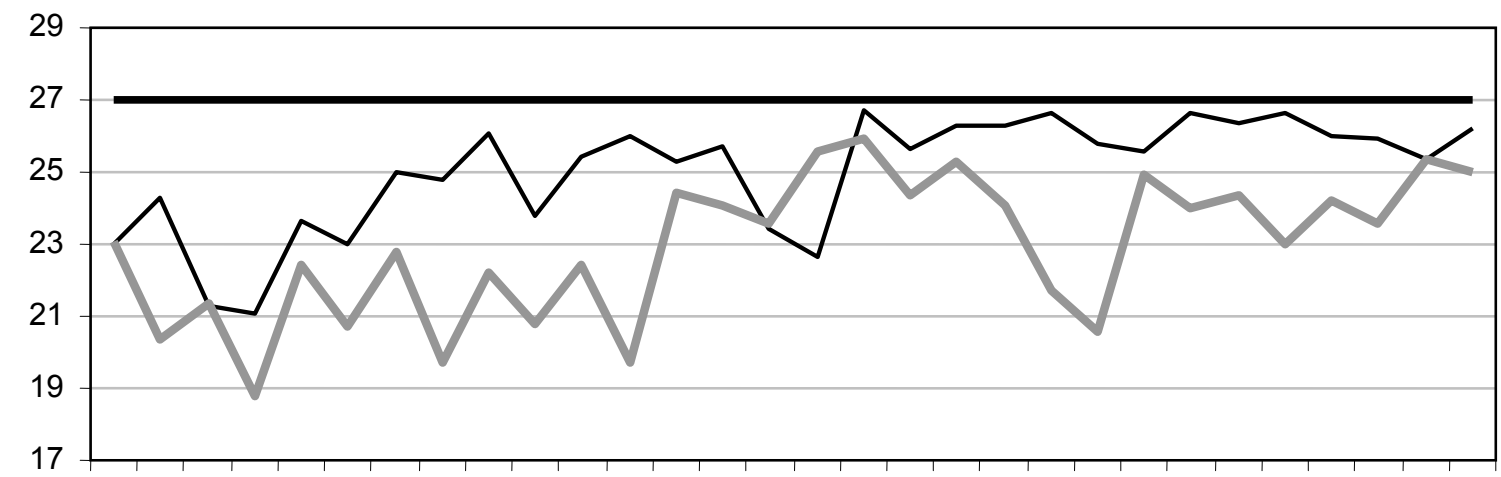

$122 \quad 3 \quad 4 \quad 5 \quad 6 \quad 7 \quad 8 \quad 9 \quad 101112131415161718192021222324252627282930$

- Equilibrium - In-kind - Income

(b) Poor Country

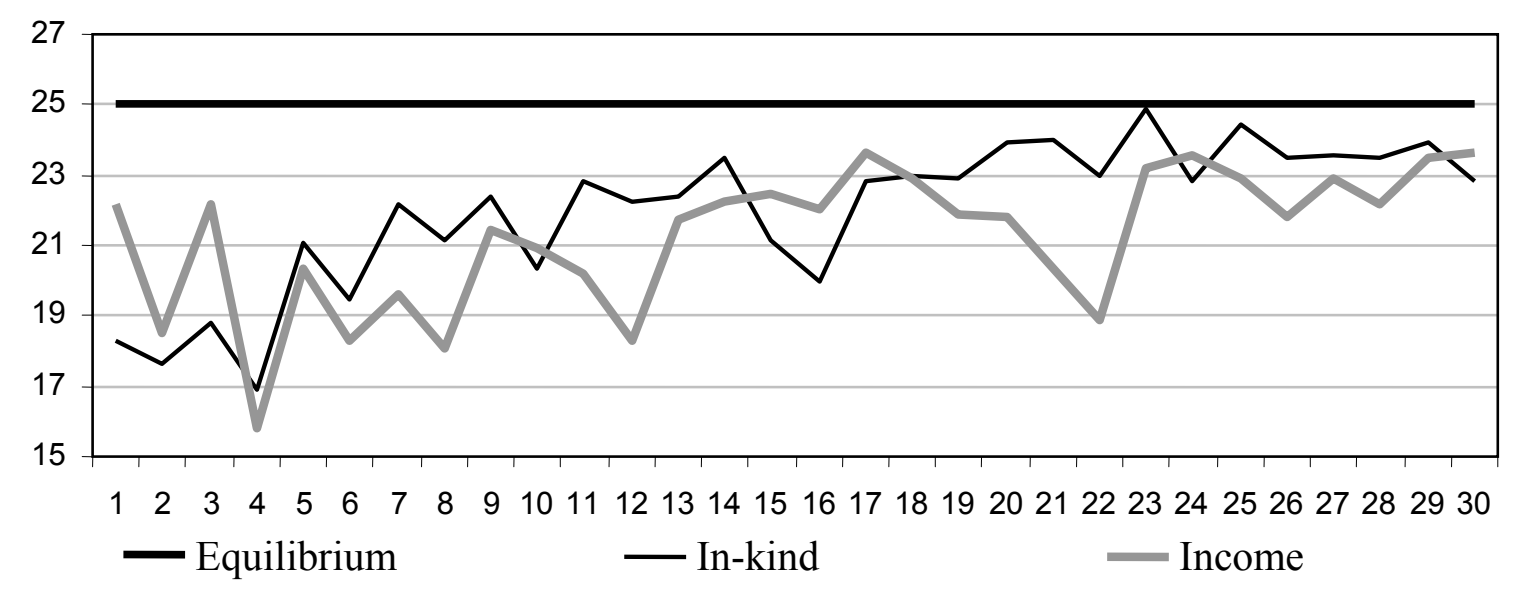

(c) Global Welfare

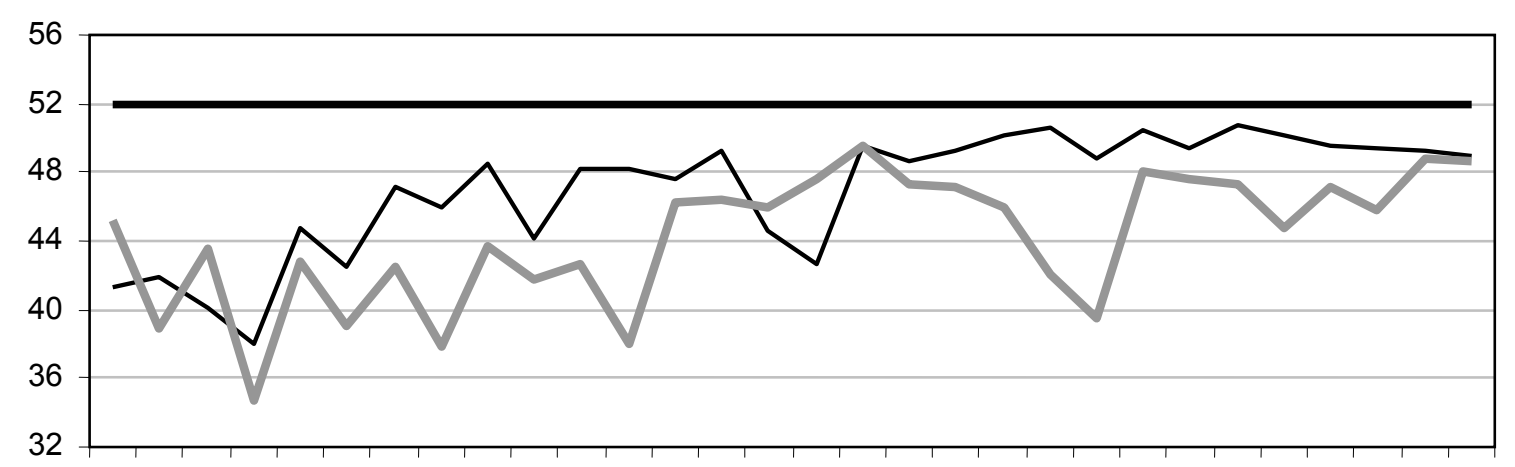

$122 \quad 3 \quad 4 \quad 5 \quad 6 \quad 7 \quad 8 \quad 9 \quad 101112131415161718192021222324252627282930$

- Equilibrium - In-kind - Income 
Figure 5: Time Series of the Aid Chosen by the Rich

\section{(a) WA}

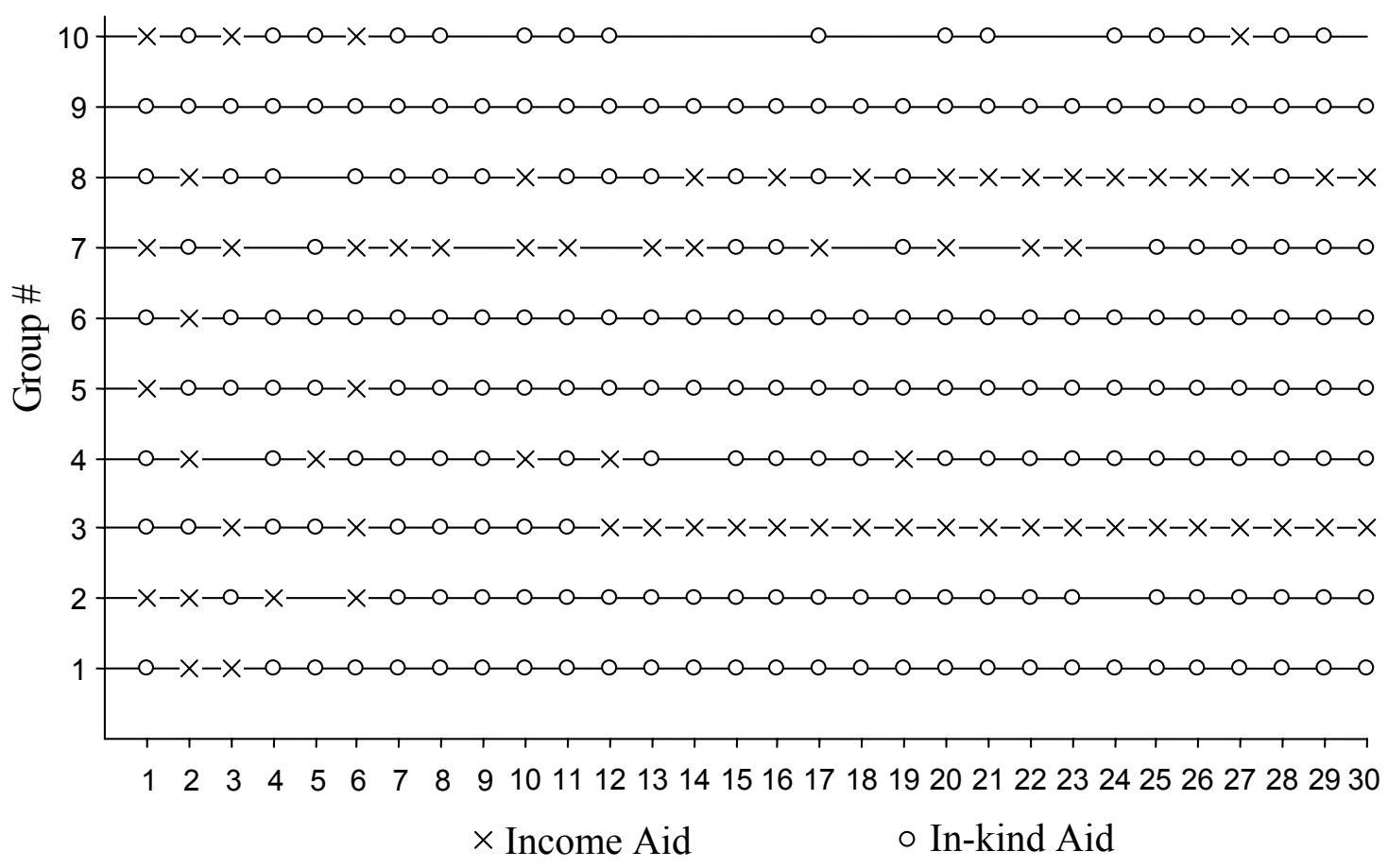

(b) SA

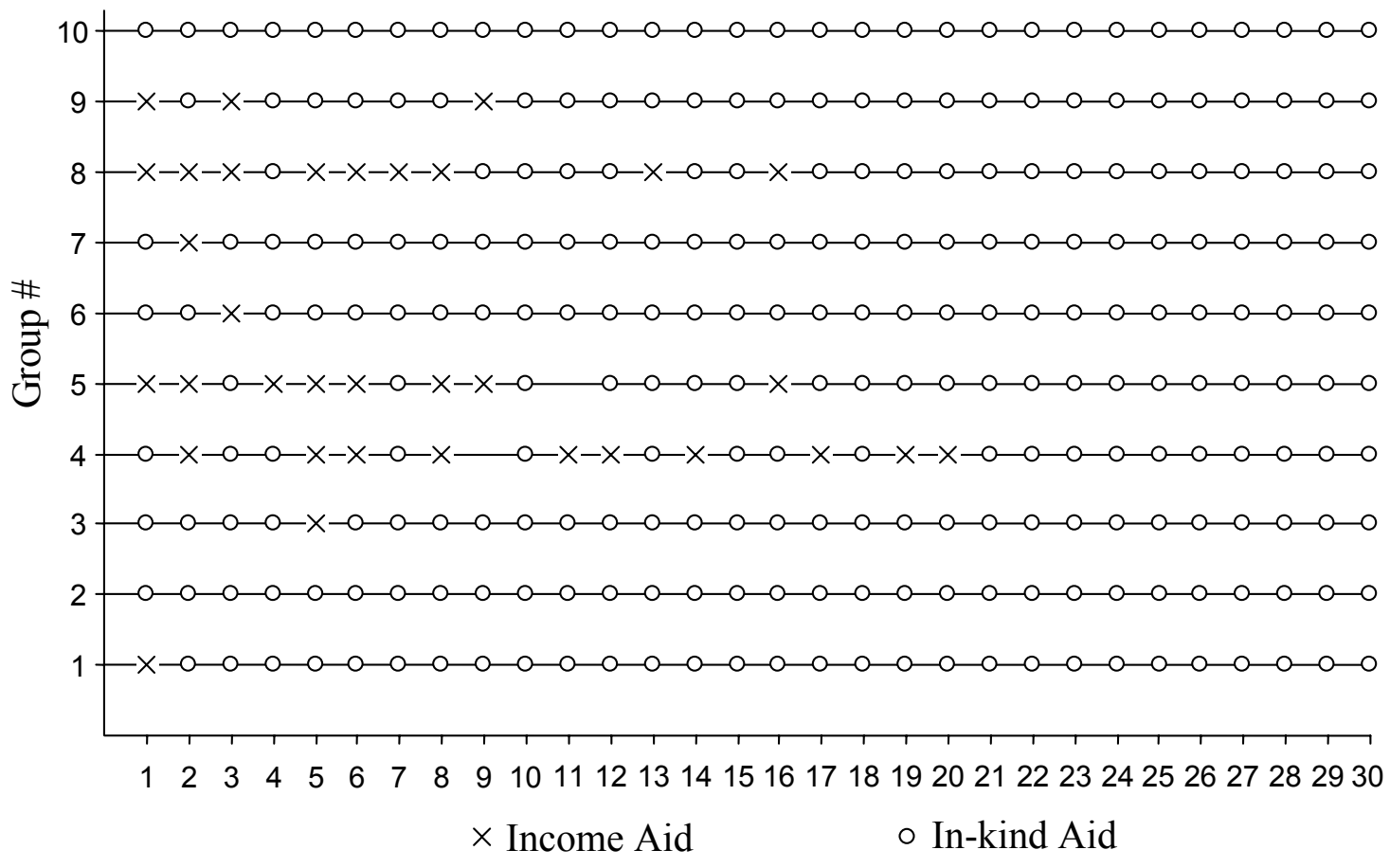

